THE BUS STOPS HERE:

RETHINKING OUR APPROACH TO BUS TRANSIT

by

Mark Sadoway

BDes, University of Alberta, Edmonton, 2005

\author{
A Major Research Paper \\ presented to Ryerson University \\ In partial fulfillment of the requirements for the degree of \\ Master of Planning \\ in \\ Urban Development
}

Toronto, Ontario, Canada, 2014

(C) Mark Sadoway, 2014 


\section{Author's Declaration}

I hereby declare that I am the sole author of this major research paper. This is a true copy of the major research paper, including any required final revisions, as accepted by my examiners.

I authorize Ryerson University to lend this major research paper to other institutions or individuals for the purpose of scholarly research.

I further authorize Ryerson University to reproduce this major research paper by photocopying or by other means, in total or in part, at the request of other institutions or individuals for the purpose of scholarly research.

I understand that my major research paper may be made electronically available to the public. 


\title{
THE BUS STOPS HERE: \\ RETHINKING OUR APPROACH TO BUS TRANSIT
}

(C) Mark Sadoway, 2014

\author{
Master of Planning \\ in \\ Urban Development \\ Ryerson University
}

\begin{abstract}
This paper will challenge the traditional approach to providing bus transit, particularly on busy high-frequency arterial routes. It posits that conventional bus services are unable to meet contemporary urban sustainability and mobility challenges. Emerging approaches, such as the various forms of bus rapid transit, hold promise as ways to improve the perception of the bus and its usefulness to current transit riders and potential riders. This study uses a survey of best practice in bus transit improvements, as well as key informant interviews with professional service planners in the transit industry. Key findings are directed at the need for new and interdisciplinary ways of working, interdepartmental coordination, a high degree of active public engagement, and physical changes to bus transit systems. The findings informed a series of recommendations to help address the image and performance of bus transit in Toronto.
\end{abstract}

Key words:

Public transit, public transit planning, urban sustainability, bus, bus rapid transit, marketing, brand 


\section{Acknowledgements}

This study emerges out of 20-some years of riding the bus and wondering if this is really the best we can do. Despite its presence on our streets and its importance to the transit riders it carries every day we are only just starting to give it a fair chance.

My guide through the study, Dr. Pamela Robinson, was instrumental in helping me recognize how the lowly bus fits into a much larger picture, one with significant repercussions for cities and city dwellers. Pamela happily took on a student seeking to research a rather unconventional topic in an unconventional way, and allowed him to put stills from The Simpsons in his MRP. And for that I am indebted.

Professor Ron Keeble leveraged his laser vision to zap superfluous punctuation and run-on sentences out of the drafts. I sincerely appreciate his feedback and assistance with this study as well as his sage guidance throughout the program.

The eight interview participants took time out of their busy schedules to engage me in novel and frank conversation. They shed light not only on the barriers but also on the potential, and they have my gratitude ... especially for the garage tour.

Finally, after a late night working on this paper and a long trip home on the bus I could always count on The Two Ladies of The House, Meredith and Zsa Zsa, for snugs and a warm welcome home. 


\section{Table of contents}

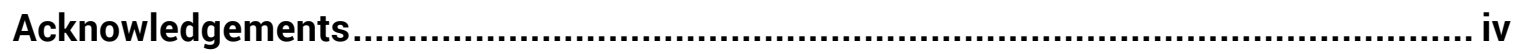

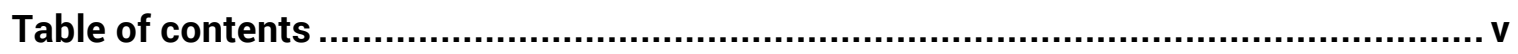

List of figures.................................................................................................... vii

List of tables ................................................................................................... vii

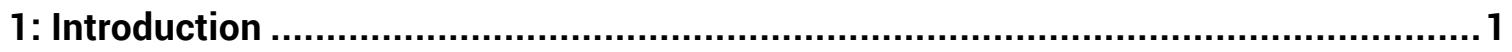

2: Literature review ....................................................................................... 4

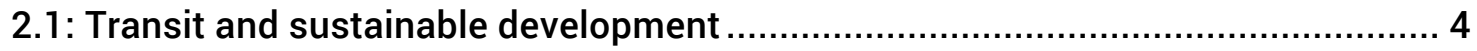

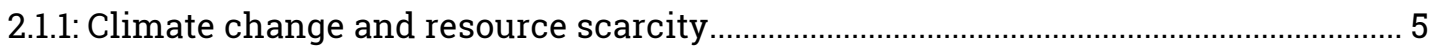

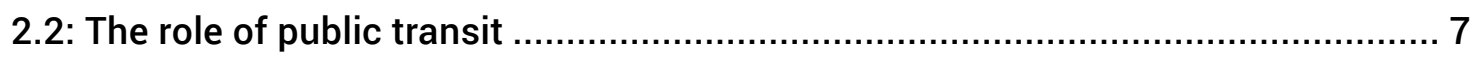

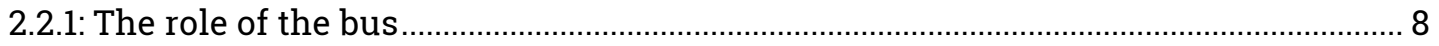

2.2.2: Rapid bus: An emergent transit product ...................................................................10

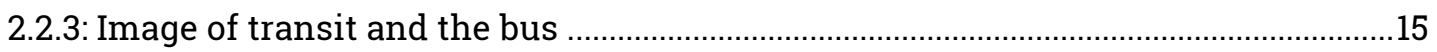

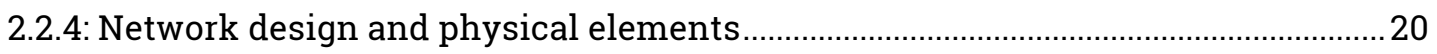

2.2.5: Comfort, convenience, safety, and waiting ............................................................ 23

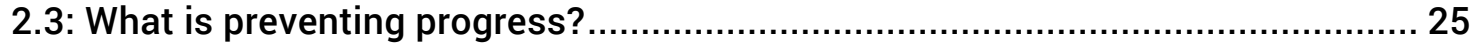

2.3.1: Spatial mismatch of rapid transit service and transit-dependent people .............. 25

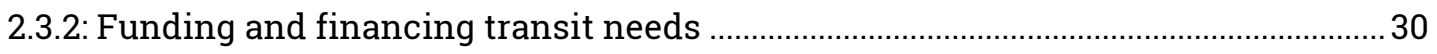

2.3.3: The silo mentality and unsustainable modes of thinking ...................................... 32

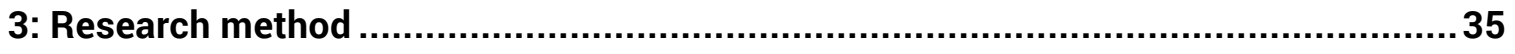

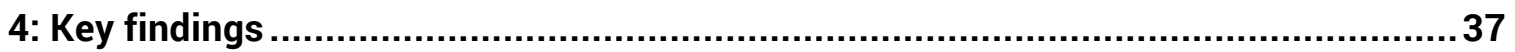

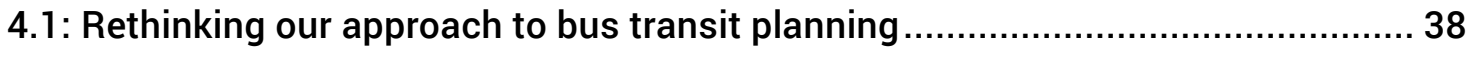

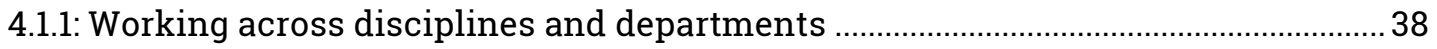

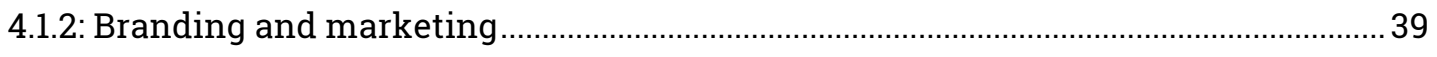

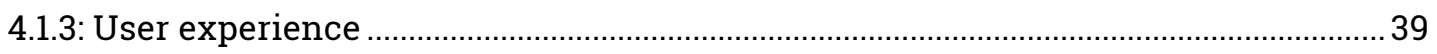

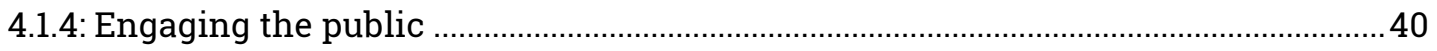




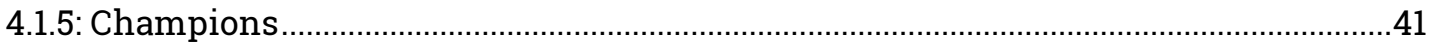

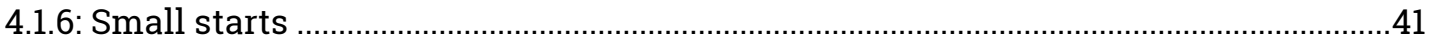

4.2: Rethinking the mechanics of bus transit ............................................... 42

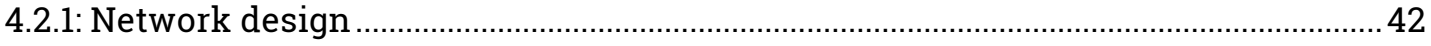

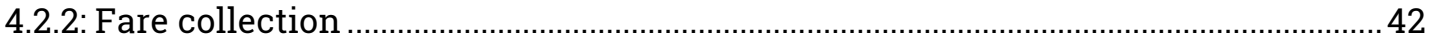

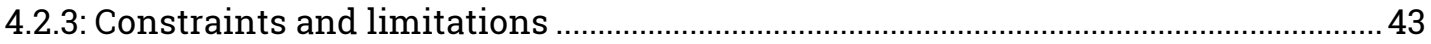

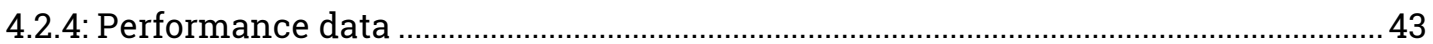

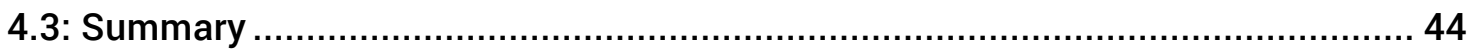

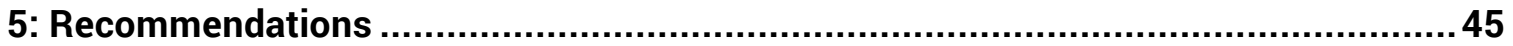

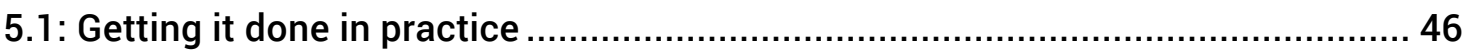

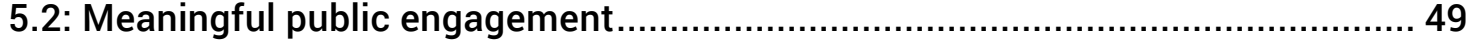

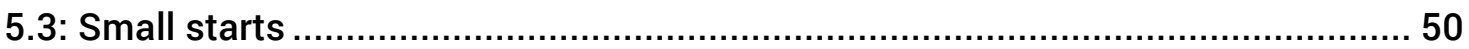

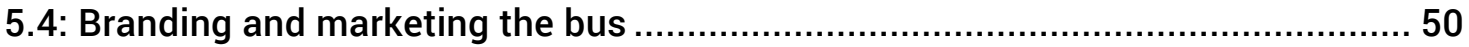

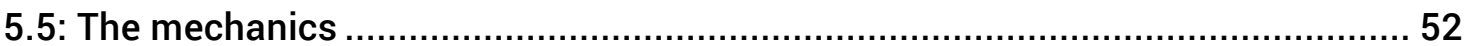

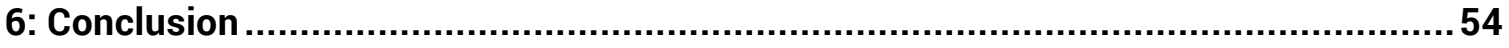

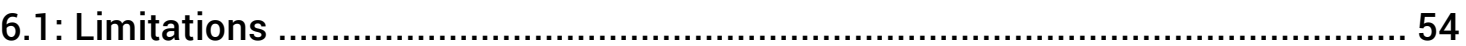

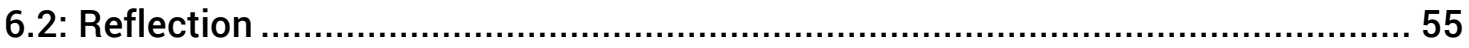

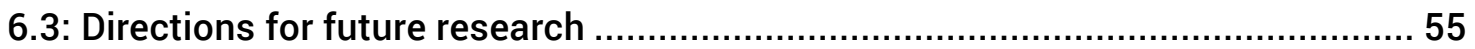

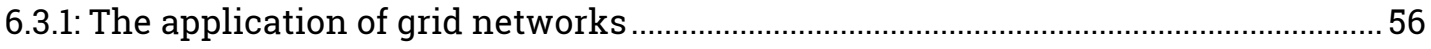

6.3.2: Ridership response to brand revitalization ............................................................. 56

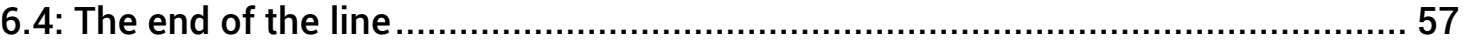

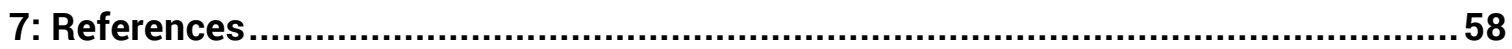




\section{List of figures}

Figure 1: Transit Trips by Mode, 2011 data (Canada and US) 8

Figure 2: Overcrowding on a TTC bus $\quad 9$

$\begin{array}{ll}\text { Figure 3: Example of a queue jump } & 10\end{array}$

Figure 4: A Rapid Ride vehicle in congested traffic in Seattle, Washington 13

$\begin{array}{ll}\text { Figure 5: The bus in popular culture } & 15\end{array}$

$\begin{array}{ll}\text { Figure 6: The bus in advertising } & 16\end{array}$

$\begin{array}{ll}\text { Figure 7: Examples of utilitarian transit brand expression } & 16\end{array}$

$\begin{array}{ll}\text { Figure 8: Examples of high-impact brand expression } & 17\end{array}$

$\begin{array}{ll}\text { Figure 9: Grid networks } & 21\end{array}$

Figure 10: Sources of delay for MTA New York City Transit buses 22

Figure 11: The hierarchy of transit needs $\quad 24$

Figure 12: Three cities in Toronto $\quad 27$

Figure 13: Creative class share of total occupations 27

Figure 14: Rapid transit service gaps and the third city 29

Figure 15: The Transit City plans $\quad 30$

Figure 16: Transit ridership in Canada, 2008 to 201231

Figure 17: Visualization of pluralistic fora and collaborative model $\quad 47$

Figure 18: BRT features "dotmocracy" game 49

\section{List of tables}

Table 1: Sample of capital costs per km by mode 12

Table 2: Capacity by mode $\quad 13$

Table 3: Boarding/alighting times $\quad 22$

Table 4: Who does what in transit projects 32

Table 5: Interview questions 36 


\section{1: Introduction}

The tableau is familiar to many. After navigating a parking lot to the nearest intersection one now stands at a bus stop, mud underfoot and the small shelter too stinky and dirty to wait in, waiting for a perpetually late bus. After 20 minutes it finally shows up in a platoon of four, two of them packed to the rafters, the third and fourth nearly empty. People disgorge from the rear doors, while those you have been commiserating with at the stop begin to file onto the front door, oneby-one, placing their fare in the farebox. The traffic signal ahead cycles green-red-green, and just as the final person gets on and the driver shuts the door, red. This happens under the gaze of passing motorists, who seem thankful that they are in their own vehicle.

This frustrating experience is common for North American transit riders and undoubtedly contributes to the negative perception of bus transit as a travel alternative. In addition to this standard of bus service, the same agencies may also operate rail lines to a higher standard, with all door boarding, proof-of-payment systems, and investment in system image. Transit properties such as Metro in Los Angeles and YRT/VIVA in York Region, Ontario, have re-imagined the user experience for bus riders. Despite daily ridership levels in the tens of thousands on arterial routes (TTC, 2011,2) Toronto's bus services are stuck in the same situation as the one described above. Why is the bus not designed to the similar service standard as rail rapid transit, despite carrying similar volumes of passengers?

Public transit in general is a hot topic in Canada's largest cities. Carbon emissions, liveability, and the economic cost of congestion are provoking debate. In the Greater Toronto Area (GTA), congestion has been found to cost the local economy $\$ 6$ billion yearly in lost productivity (HDR, 2008). Further, changing settlement patterns and the distribution of suburban employment in the GTA have placed rapid public transit out of reasonable reach of the market who needs it most: recently settled immigrants, people of limited economic means working multiple jobs, the working and service classes (Martin Prosperity Institute, 2012).

Metrolinx, the regional transportation planning agency, approved The Big Move plan in 2008, which set out an ambitious 25-year agenda to built a multi-modal transportation network throughout the Greater Golden Horseshoe (GGH)(Metrolinx, 2008). Some municipalities within the GGH, such as York Region and Brampton, have already implemented improved bus-based rapid transit systems, generally known as bus rapid transit (BRT). But in Toronto, many riders spend numerous hours per day in transit on TTC buses (Grewal, 2006), and the Toronto Transit 
Commission (TTC) bus network is often viewed as overcrowded, unreliable, and prone to "bunching"1 (TTC Riders, 2014; Munro, 2012). Despite a series of reports by the TTC looking at improvements to bus service on Finch Avenue West in 2011 (TTC, 2011), little attention has been paid to making holistic improvements to the bus network.

2014 is a civic election year in Toronto, and some voices are calling for improvements to the TTC's bus network. For example, in his Grid article entitled "Steal this platform!" Keenan (2014) invites mayoral candidates to "get on the bus" and asserts that transit modes such as BRT would be useful in improving the quality of life for transit-dependent people in the short term. One mayoral candidate, Olivia Chow, seems to have somewhat embraced this idea, and is promising additional bus service (Chow, 2014). Further, Josh Colle, a city councillor, has requested the TTC look into the prospect of adding express buses to improve service (Kalinowski, 2014). Perhaps we have forgotten that a plan already exists to improve the bus network. The Transit City Bus Plan was approved in 2009 and was designed to complement the Transit City Light Rail Plan. Toronto City Council cancelled the light rail plan in 2010, and only a few components of the bus plan have been implemented by the time of this writing.

This paper will suggest that it is time to get serious about the bus. Transit demand is high now and short-term solutions to urban mobility challenges are needed. Public resources are limited and rail lines are expensive. How can bus transit be improved and what is preventing progress in improving it? This research paper seeks to investigate these issues through the lenses of sustainability, mobility, and the role of the planner. The following research questions will be addressed:

- How can bus transit be positioned as a credible and attractive alternative to the automobile?

- What overall strategies appear to be the most successful?

- To what degree were new approaches sought in working with stakeholders and other disciplines (engineers, communications and marketing staff, administrators, etc.)?

This research paper will begin in section 2 by reviewing how the transit bus can be one solution to sustainable development and urban mobility challenges, suggest new approaches to providing bus transit, and identify possible barriers to implementing such changes. The TTC bus network will be used as the lens through which recommendations will be made. Sections 3 and 4 will

\footnotetext{
${ }^{1}$ Bunching is when numerous buses arrive at once, after a long headway gap.

${ }^{2}$ Also referred to as "choice" riders. Walker (2012) disputes the use of the captive/choice binary. He points out that
} 
detail the results of a series of interviews with key informants who have been responsible for driving change in bus transit systems. Finally, in section 5, the interview findings will inform recommendations on how to advance new approaches to bus transit in Toronto along with direction for future research and a reflection on what the findings mean from the planner's perspective. The paper concludes with section 6 , where the scope of analysis is brought back to the planner and additional questions are set out for future research. 


\section{2: Literature review}

Public transit serves a number of functions including providing a mode of transportation that is more sustainable than conventional automobiles in terms of space efficiency and congestion reduction, greenhouse gas emissions reduction, and improving mobility for those without access to an automobile (Vuchic, 1999; Amin, et al., 2013). The primary mode for public transit is the transit bus, a vehicle that does not have a particularly polished reputation (Hemily and King, 2008; Cain, et al., 2009; Grescoe, 2012).

\section{1: Transit and sustainable development}

Despite the signing of the 1992 Rio declaration and the 2007 Kyoto Protocol, the publishing of the Brundtland Report (Our Common Future), the Stern Review, and the five series of reports from the Intergovernmental Panel on Climate Change (IPCC), the seemingly overwhelming momentum of increasing emissions and energy consumption in industrializing and post-industrial countries has continued apace (Stocker, et al., 2013; Amin, et al., 2013).

It is generally recognized that shifting travel behaviour toward more sustainable options such as public transit is a critical component of improving urban mobility and urban sustainability (Vuchic, 1999). However, public transit must have a higher average mode share than is currently the case in North America's cities if we wish to use it as an effective tool to reduce overall carbon emissions (Mees, 2010). Currently, there are not enough riders per transit vehicle kilometre, and insufficient emission and fuel consumption controls (Kahn Ribeiro, et al., 2007).

The need to increase investment in public transit infrastructure stems from several converging issues, namely access to employment and cultural opportunities, reduced economic output due to congestion, and climate change due to transport sector emissions. These three issues align with the generally agreed-upon sectors of sustainable development: ecological preservation, social justice, and economic growth and efficiency (Campbell, 1996; Dale, 2001). Therefore, to be sustainable is to be concerned with more than emissions; we must also consider accessibility, which is the ability to reach a destination in order to work, play, seek health services, participate in civic activities, etc. (Amin, et al., 2013).

On balance, evidence points to the fact that significant changes must be made to the way we plan, operate, and invest in transit, given the present auto-dependency in North America. Trends of increasing urbanization, affluence, congestion, and greenhouse gas (GHG) emissions in the 
developing world also reinforce the need for systems change (Amin, et al, 2013; Suzuki, Cervero, and Iuchi, 2013).

\subsection{1: Climate change and resource scarcity}

Climate change does not only affect the biosphere. It also affects the human environment that exists within it, including settlements, infrastructure, economy, food and water supplies, health, and political systems. A forthcoming report from the IPCC (Fifth Report, Working Group II) has forecasted significant disruptions if worldwide average temperatures continue to increase beyond pre-industrial levels. These disruptions include crop failure, drought, flooding, and rising sea levels. They may negatively affect ongoing adaptation efforts in economic and human health systems. Further, they could possibly cause civil strife and interregional conflict (Field, et al., 2014).

The first factor in urban sustainability in the face of a changing climate is oil and its availability. In 2004, 93 percent of the energy consumed in Canada for propulsion in the transportation sector was oil-based (97 percent in the United States)(IEA estimates, from Lerch, 2007). In 1973, worldwide oil consumption was around 2 billion tonnes of oil equivalent and the transportation sector consumed 45.4 percent of that amount. By 2010, consumption had grown to 3.5 billion megatonnes of oil equivalent and the transportation sector consumed 61.5 percent of that amount (IEA estimates, from Amin, et al., 2013, 11). Further, worldwide trends show increasing autoownership rates and vehicle-kilometers travelled in developing countries, as auto ownership and mobility is often tied to economic growth and status (Amin, et al., 2013, 4). Although emissions reduction and travel behaviour change are being accomplished in the North American and European context, overall emissions will continue to rise due to increased energy consumption in developing countries (Amin, et al., 2013, 31).

As private automobile fleets grow the risk of demand for oil exceeding supply becomes more acute. "Peak oil" occurs when worldwide oil production begins to enter terminal decline due to the consumption of over half of the recoverable reserves and estimates of its timing vary considerably. One can only know the timing of peak oil production after it has occurred and oil production rates are in decline (Lerch, 2007). The general consensus is that a peak is inevitable because oil reserves are finite. In any case, many observers are anticipating extreme volatility of petroleum prices and supply, and serious impacts for energy-dependant Western economies (Kunstler, 2005; Lerch, 2007; Heinberg, 2011). 
The second factor of urban sustainability is carbon emissions, and when examining transportation, the emissions from this sector are of particular importance. In the United States, the transportation sector is responsible for 28 percent of national carbon emissions, and those emissions have increased by 18 percent since 1990 (US EPA, 2013). In Canada, an estimated 170 megatonnes of CO2 was emitted by the transportation sector in 2011 (out of a national total of 702 megatonnes). Private automobiles alone (cars, light trucks, motorcycles, etc.) emitted 88 megatonnes. Private transport emissions are projected to decrease to 81 megatonnes by 2020 , due to improved fuel efficiency standards, but freight transport emissions are forecast to increase overall transport sector to 176 megatonnes by 2020 (Environment Canada, 2013).

The concept of resilience and adaptation has emerged in response to the dual emerging threats of climate catastrophe and resource scarcity (Roseland, 2012). One of the main factors in building resiliency is to reinforce the importance of efficient transportation choices (public transit being among them) in what Gomez-Palacio (2014) refers to as "transit urbanism." Further, GomezPalacio and Suzuki, Cervero, and Iuchi (2013) argue that public transit can only have success in increasing urban sustainability if it is closely integrated with land use planning and policy. Indeed, many municipalities across North America appear to be grasping this concept and are adopting complete streets, integrated land use plans, and transit oriented development policies (see City of Edmonton, 2009, and Chicago Dept. of Transportation, 2013).

Public transit is one part of a toolkit for addressing urban sustainability. Other tools span building design to social inclusion (Roseland, 2012). But since the transport sector is responsible for a substantial portion of energy consumption and emissions, and since populations are becoming increasingly urbanized and mobile, shifting urban travel behaviour to favour public transit will play a large role. To accomplish this, discretionary riders ${ }^{2}$ (people who have access to different options in how they travel) need to be lured to use public transit more often. Investments in rapid transit and operational changes need to be made to make transit more attractive against its main competitor, the private automobile (Vuchic, 1999; Cain, et al., 2009; Mees, 2010; Webber, Arpi, and Carrigan, 2011). While not the sole answer, transit is one component of a larger and localized solution to a global problem.

However, implementation continues to be a struggle. The contemporary metropolitan form in many of North America's city regions is no longer conducive to making transit a realistic option

\footnotetext{
${ }^{2}$ Also referred to as "choice" riders. Walker (2012) disputes the use of the captive/choice binary. He points out that most people have some choice in transportation mode and lie on a spectrum somewhere between captive and discretionary.
} 
for many and high capacity rapid transit no longer serves transit-dependent, lower-income markets (Bertaud, Lefèvre, and Yuen, 2011; Tomer, Kneebone, Puentes and Berube, 2011). Further, resources are a perennial constraint on both capital investment and service (Amin, et al., 2013; FCM, 2007), and an institutional silo mentality in municipal planning and operating agencies prevents integrated solution finding (Dale, 2001).

\section{2: The role of public transit}

Public transit is commonly regarded as a more efficient way of moving people around an urban environment than the private automobile as it far less space-consumptive than the car (Vuchic, 1999). For some trips, namely the "radial" commute mentioned above, public transit is often competitive with the car if the total travel time (which includes finding parking) is taken into consideration (Litman, 2013). In the United States, on average, transit travel times are typically two or more times greater than automobile travel times due to the dispersion of land uses (Pisarski, 2006, 109).

The relationship between public transit and emission reductions is far less certain than the relationship to morphology and land use. The Fourth IPCC Transport Working Group was reluctant to state with confidence that public transport can reduce emissions, noting that the effect on emissions is related closely to land-use/transit integration, urban form, and density:

Providing public transport systems and their related infrastructure and promoting non-motorized transport can contribute to GHG mitigation. However, local conditions determine how much transport can be shifted to less energy intensive modes. Occupancy rates and primary energy sources of the transport mode further determine the mitigation impact. The energy requirements for urban transport are strongly influenced by the density and spatial structure of the built environment, as well as by location, extent and nature of transport infrastructure (Kahn Ribeiro, et al., 2007, 326).

For example, Bertaud, Lefèvre, and Yuen (2011) found that in dense urban areas such as New York City, transit (and the bus in particular) emits far fewer GHGs per passenger kilometer than the private auto (230 grams of $\mathrm{CO} 2$ per passenger kilometre travelled for gasoline-powered cars, compared to 33 for a diesel transit bus). The problem, as the IPCC working group indicated, is that the emissions depend on per passenger rates. If there are many passengers on transit buses the emissions benefits are obvious. But if there are few passengers on transit buses (the very case in many North American cities), the emissions benefits are uncertain at best. One direction to improve the effectiveness of transit in suburban auto-dependent environments is to alter the landuse patterns to be a higher-density, mixed-use, transit oriented design (Roseland, 2012) and 
leverage the location advantage of transit to help finance this redevelopment (Dunphy, 2004). To the contrary, Mees (2010) notes that it far more realistic and timely to address transit needs in existing built-up areas, no matter how suburban in built form, than it is to engage in the heroic effort to remake the suburbs to be more like urban cores.

\subsection{1: The role of the bus}

The transit bus has been a workhorse of public transit fleets since the 1950s (Vuchic, 2007). They make up around 40 percent of the United States transit fleet (2012 data, APTA, 2013), compared to 8 percent in rail vehicles. In 2011, around 54 percent of unlinked transit trips in the United States and 64 percent of trips to work in Canada were taken by bus (Figure 1) ${ }^{3}$ (APTA, 2013; Statistics Canada, 2012). In Toronto, buses still provide an essential aspect of a multi-modal fleet, including the line-haul arterial routes that connect to the streetcar and heavy rail subway network (Mees, 2010). In 2012, TTC buses carried 235 million unlinked trips, or 45.6 percent of total trips (TTC, 2013).

Figure 1: Transit Trips by Mode, 2011 data (Canada and US) APTA, 2013; Statistics Canada, 2012

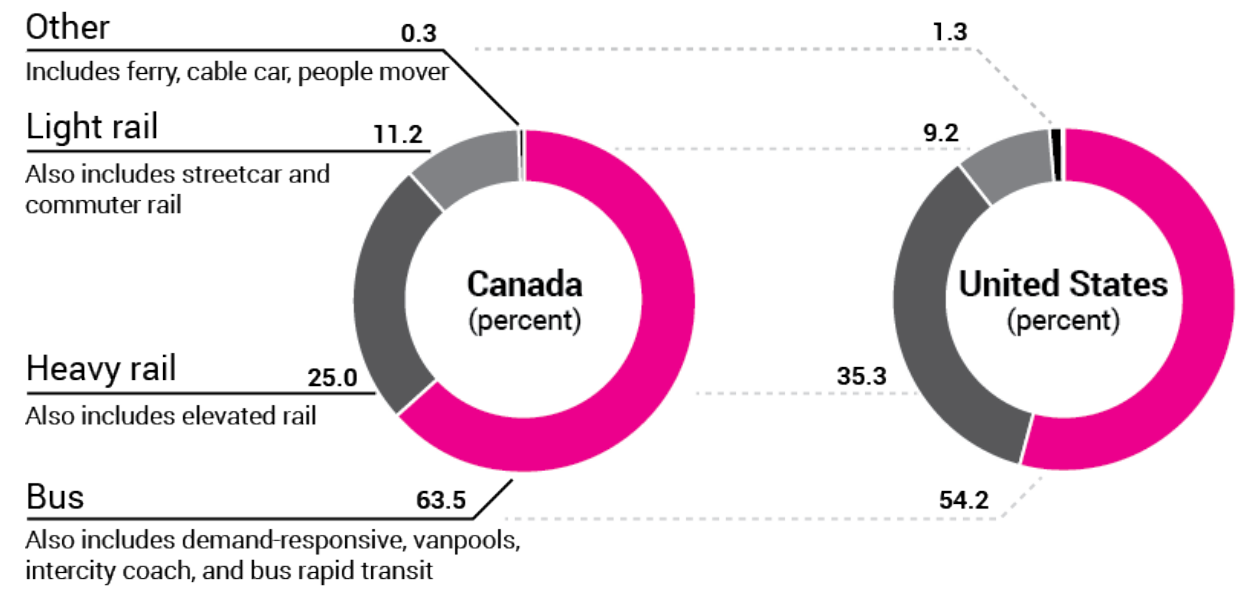

In planning and transit engineering literature the transit bus is often described as "flexible" (Sendich, 2006) with little "razzmatazz" (Dunphy, 2004). Due to the street-running nature of bus service, it provides the ability to change route alignments easily (Dunphy, 2004), and is seen as an "inferior" substitute for a rail spine (Newman and Kenworthy, 1999) and a low cost solution to serve dispersed areas (Vuchic, 2005). Walker (2012) suggests that buses can be suitable to serve

\footnotetext{
${ }^{3}$ This chart is intended to illustrate the role of the bus in contemporary North American transit, and not intended as a Canada/US comparison. The methods of data collection differ. The US data are total unlinked trips by transit as reported by agencies and the Canadian data are trips to work as reported by 2011 National Household Survey respondents.
} 
high-ridership corridors and questions the desirability of "flexible" services as they tend to add complexity to a route structure and make transit confusing to discretionary riders (Walker, 2012).

The TTC bus in Toronto provides a convenient grid of high-frequency routes that provide service to suburban transit riders. However, bus riders experience unreliable and unpredictable service (Munro, 2012; Topping, 2013). In early 2014, the Toronto transit advocacy group TTC Riders began a Twitter campaign (called "TTC Sardines") to visually capture overcrowding on the TTC network (TTC Riders, 2014; one such tweet, submitted by R. Ong, appears as Figure 2). The New York City transit advocacy group Straphangers awards the annual "Pokie" and "Schleppy" awards to the least reliable and slowest bus routes in the Metropolitan Transportation Authority (MTA) network. 2013's winners were the M42 $42^{\text {nd }}$ Street Crosstown and the M50 49/50 ${ }^{\text {th }}$ Streets Crosstown, which had reported average trip speeds of $3.4 \mathrm{mph}(5.5 \mathrm{~km} / \mathrm{h})(\mathrm{NYPRIG}, 2013)$. The MTA's own reported measurements tend to agree, noting a system-wide average speed of 8.1 $\mathrm{mph}(13.4 \mathrm{~km} / \mathrm{h})$ and the slowest average speed among peer agencies (2006 data, NYDOT/MTA, 2009a).

Figure 2: Overcrowding on a TTC bus (Ong, R., 2014; from TTC Riders, 2014)

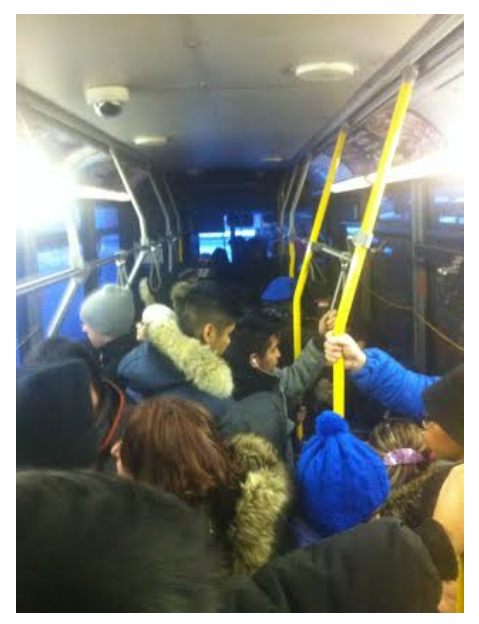

In addition to crowding, there are physical factors that affect the perception of transit. Transit agencies, traditionally focused on serving radial suburb-to-centre trips, are no longer providing services where potential markets require it (Brown and Thompson, 2011; Tomer, Kneebone, Puentes and Berube, 2011). Rail rapid transit in most jurisdictions does not appear positioned to address these challenges. Some agencies are making small and bold steps to rethink the way they plan and operate bus transit services to adapt to new suburban morphologies and travel patterns. 


\subsection{2: Rapid bus: An emergent transit product}

One of the objectives of this research is to identify how to improve bus transit. A potential application appears to be in the form of an emergent type of transit product offering which has appeared in many cities throughout Canada and the United States since the mid-2000s. This type of product tends to be labeled by its proponents (transit agencies, departments of transportation, etc.) as "bus rapid transit," and consists of some combination of BRT-like elements such as low floor articulated vehicles, a unique brand image, frequent all-day service, wide stop spacing, larger station stops, off board fare collection, real time arrival displays, level curb boarding, and transit priority measures (NYDOT/MTA, 2009a; Metro Transit, 2014). The application of the term "BRT" to these types of services is disputed by some due to the absence of a dedicated running way to protect the operation of transit vehicles from intrusion by automobiles and traffic congestion (ITDP, 2013). Others have suggested new terminologies for this type of product, such as "bus with higher level of service" (Finn, 2010), "bus transit system" (Vuchic, 2005), or "BRT-lite" (Pessaro, et al., 2011). The term "rapid bus system" will be used here to refer to this service concept.

Whatever the name, the first key common characteristic with this product is that it does not feature a segregated guideway throughout the transit corridor to separate transit vehicles from general auto traffic. Some rapid bus corridors do not have bus lanes or dedicated road space at all (Pessaro, et al., 2011). Instead, the service relies on other physical and technical interventions such as queue jumps (Figure 3), bus lanes through pinch points, transit signal priority (TSP), curb bump-outs, etc. (Vuchic, 2007; NYDOT/MTA, 2009a). These physical elements are combined with frequent, "forget the timetable" all-day service (every 15 minutes or less) and a distinctive brand or logo to improve system image and distinguish the line from other bus routes (Pessaro, et al., 2011).

Figure 3: Example of a queue jump (from TTC, 2011)

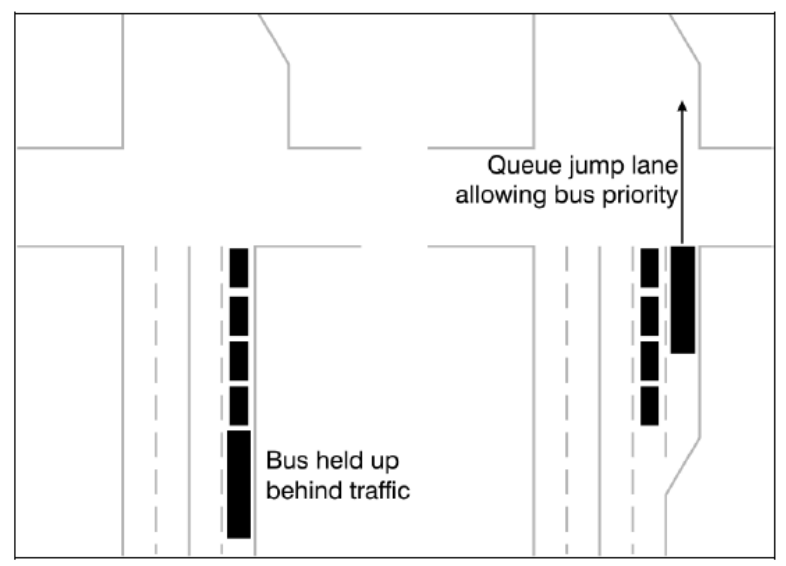


Securing right-of-way is generally considered the single most effective method of improving the speed, reliability, and attractiveness of transit service (Levinson, et al., 2003; Vuchic, 2007; Bruun, 2014). It is also expensive and time consuming to implement, and it is often difficult to find space for dedicated busways on busy urban streets (NYDOT/MTA, 2013). Consequently, many agencies, particularly in the United States, have implemented this less intensive type of rapid bus service. Examples include:

- Select Bus Service in New York City

- MAX in Kansas City, Missouri

- Metro Rapid in Los Angeles

- Valley Metro LINK in Phoenix, Arizona

- Capital Metro Rapid in Austin, Texas

- RapidRide in Seattle, Washington

- Cedar Avenue BRT in Minneapolis/St. Paul, Minnesota.

A website review of these agencies revealed multiple lines in service and most have plans for expansion in the near future. Canadian examples are fewer in number, but include:

- B-Line routes in Vancouver, British Columbia

- 300-series BRT routes in Calgary, Alberta

- Zum in Brampton, Ontario

- VIVA in York Region, Ontario

- 400-series Express routes in Montreal, Québec

- DART in Saskatoon, Saskatchewan

- MetroLink in Halifax, Nova Scotia

- Pulse in Durham Region, Ontario

\section{Advantages of rapid bus systems}

Given the image issues with the bus, what promise, if any, does it provide in terms of addressing sustainability and mobility issues that face metropolitan regions? To address this question it would be useful to review some distinct advantages of rapid bus services over other more costly modes. It is also important to recognize that each mode has its place. As Walker (2012) notes, BRT, LRT, and heavy rail metro ("subway") are like tools in a toolbox. In other words, you normally do not use a screwdriver to hammer a nail. 
The primary advantage of on-street BRT is reduced capital costs in comparison to full BRT and rail modes. Capital costs vary depending on local circumstances, the degree of right-of-way separation of the planned infrastructure, and the planned intensity of service required to handle projected demand (Vuchic, 2007). Table 1 summarizes a sampling of approximate costs by mode.

Table 1: Sample of capital costs per $\mathrm{km}$ by mode

\begin{tabular}{|c|c|}
\hline On-street BRT Service & Cost (approx.) per kilometer (\$millions) \\
\hline MetroRapid (Los Angeles) & $\$ 0.128$ US (Pessaro, et al., 2011) \\
\hline MAX (Kansas City) & \$2.18 US (Pessaro, et al., 2011) \\
\hline Bx12 Select Bus (New York City) & $\$ 0.714$ US (NYMTA/DOT, 2013) \\
\hline Metro Rapid (Austin) & \$0.898 US (Capital Metro, 2012) \\
\hline Zum (Brampton) & \$3.8 CAN (Brampton, 2005) \\
\hline Full BRT Service & Cost (approx.) per kilometer (\$millions) \\
\hline SilverLine (Boston) & \$12.1 US (Pessaro, et al., 2011) \\
\hline HealthLine (Cleveland) & \$28.1 US (Pessaro, et al., 2011) \\
\hline Rail Modes & Cost (approx.) per kilometer (\$millions) \\
\hline LRT (Edmonton, Alberta, light rail) & $\$ 16.0$ US (Vuchic, 2007) \\
\hline Blue Line (Los Angeles, light rail) & \$26.2 US (Vuchic , 2007) \\
\hline Green Line (Washington, DC, heavy rail metro) & \$85.7 US (Vuchic , 2007) \\
\hline Red Line (Los Angeles, heavy rail metro) & \$203 US (Cain, et al., 2009) \\
\hline \multirow{4}{*}{\multicolumn{2}{|c|}{$\begin{array}{l}\text { It is generally accepted that transit riders prefer rail, due to perceptions about its permanence and } \\
\text { ride quality. This is usually referred to as rail mode bias (Cain, et al., 2009; Henry and Litman, } \\
2013 \text { ). However, the link between rail and overall impact on user preference is uncertain. Cain, et } \\
\text { al. (2009) conducted a survey and interview study on transit riders in the Los Angeles area and }\end{array}$}} \\
\hline & \\
\hline & \\
\hline & \\
\hline light rail and BRT modes performed comp & ly with the heavy rail metro line, while only \\
\hline quiring a fraction of the capital costs. & \\
\hline
\end{tabular}




\section{Limitations of rapid bus systems}

Figure 4: A Rapid Ride vehicle in congested traffic in Seattle, Washington (Harrison, 2012)

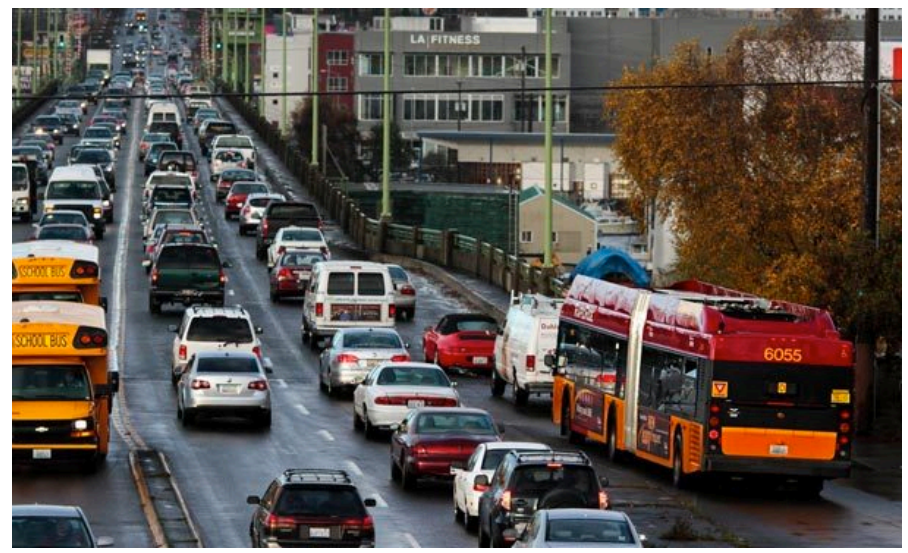

There are limitations to the rapid bus product that curtail its applicability in the urban transportation context. There are specific locations where it is warranted, but beyond a threshold additional investment in other modes such as fully separated BRT, light rail, commuter rail, or heavy rail metro would be more appropriate.

For example, there are capacity and throughput limits on bus services. The typical and feasible limit of on-street BRT capacity is around 2000 pphpd (passengers per hour per direction), which is equivalent to a articulated low floor bus, fully loaded to the crowding limit, every 3 minutes. As the rate of capitalization increases, and the mode switches to rail (which allows for coupled multi-vehicle consists), capacities increase dramatically (Table 2). This indicates that on-street rapid bus systems are limited to corridors where demand does not exceed the feasible capacity, or the overcrowding would compel riders to seek alternatives.

Table 2: Capacity by mode (Vuchic, 2005, 2007)

\begin{tabular}{ll} 
Mode & Theoretical capacity $($ pphpd) \\
\hline Bus on street & $3000-6000$ \\
\hline Separated BRT & $6000-24,000$ \\
\hline Separated light rail rapid transit (LRRT) & $10,000-28,000$ \\
\hline Separated heavy rail rapid transit & $40,000-70,000$
\end{tabular}

The draw of new ridership to a transit corridor is typically affected by vehicle mode, with rail generally out performing bus transit in terms of ridership attraction (Currie and Wallis, 2008; Currie and Delbosc, 2013; Henry and Litman, 2013). Australian data shows that, all else being equal, the implementation of a separated busway (full BRT) has a +6.8 percent effect on corridor 
ridership, while the opening of a fully separated light rail line would have a +8.5 percent effect. The opening of a heavy rail metro would increase ridership by 13.2 percent (Currie and Wallis, 2008). However, with regard to bus services, United Kingdom data revealed other factors that tend to influence ridership attraction, such as simplifying a route network, promotion and service branding, high quality wayfinding, and bus stop improvements (Currie and Wallis, 2008).

Further, the recently implemented rapid bus services noted above seem to be demonstrating considerable success, both in attracting riders and streamlining operations. For example, the Bx12 Select Bus Service saw a ridership increase of 6.3 percent over the year following implementation (2008), despite a system-wide ridership decrease of 1 percent. A 20 percent decrease in end-toend running time was also achieved, and dwell times at stops were reduced by around 24 percent by implementing off board fare collection (NYDOT/MTA, 2009b). In Los Angeles, the Metro Rapid Wilshire/Whittier corridor saw a ridership increase of 42 percent after implementation and a reduction in running time of 29 percent (Pessaro, et al., 2011).

The development of on-street BRT, particularly in the United States, has demonstrated considerable effectiveness at boosting ridership for a lower capital cost than rail. This has been attributed to both the tangible and intangible aspects of these services. For example, a number of transit officials interviewed by Pessaro, et al. (2009) who were involved in the planning of rapid bus services identify the brand and vehicle styling as being integral to the success of the service in addition to the route performance and physical interventions such as bus lanes and TSP. 


\subsection{3: Image of transit and the bus}

\section{Figure 5: The bus in popular culture}

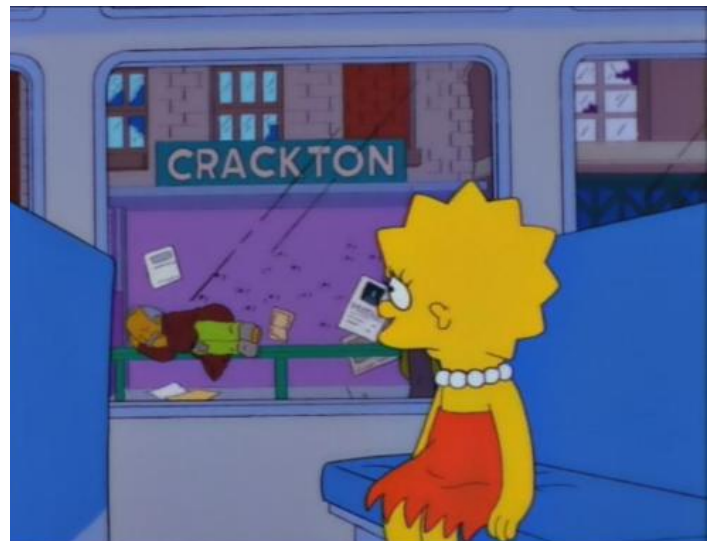

A Springfield bus stop from The Simpsons (Simpsons Wiki, n.d.)

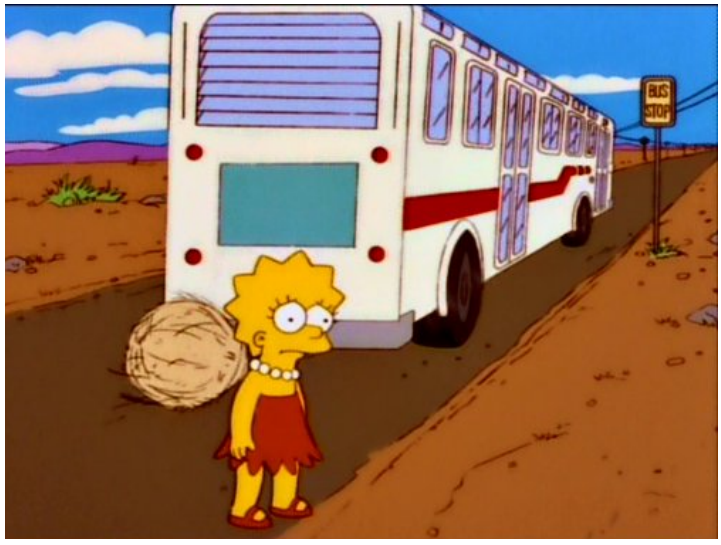

"I should've got off at Crackton ..." Lisa is left at the end of the line (Simpsons Wiki, n.d.)

Public transit in North America suffers from a brand image problem, and this negative image appears to be particularly acute when referring to the bus (Cain, et al., 2009; see also Figures 5 and 6). Referring to the Gold Line light rail service in Los Angeles, Grescoe $(2012,52)$ writes: "it makes even the newest city bus feel like the lurching, cramped, traffic-snagged, second-class ride that it is." Terms such as "loser cruiser" and "vomit comet" are commonly used to refer to buses (see Sparling, 2013, and Aguirre-Livingston, 2013, for Canadian references for these terms). The people riding buses are often perceived as being low-income earners or people who have absolutely no mobility alternative (Cain, et al., 2009). This type of public opinion supplies creative inspiration for the marketers of transit's chief competitor, the automobile. Figure 6 demonstrates the treatment of bus transit in advertising.

The problem is compounded by the frequent treatment of the transit brand identity by agencies as an afterthought, if it is addressed at all. For example, in gathering information by surveying various transit agencies, this author noted a distinct "unevenness" in how many agencies portrayed themselves in terms of graphic identity and brand voice to the riding public. Many transit agencies use dated logos, vehicle liveries that could be described as "white it n' stripe it," and inconsistent or disjointed graphic elements (Figure 7). Other agencies have invested substantial resources and time into creating a consistent and high-impact brand image (Figure 8). 


\section{Figure 6: The bus in advertising}

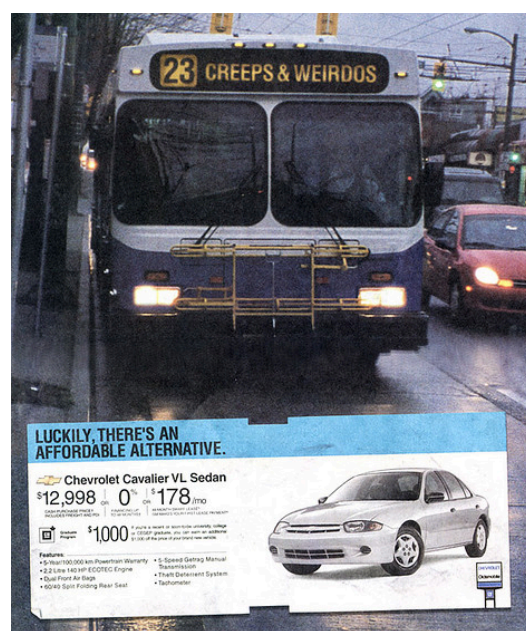

Chevrolet advertisement (Layman, 2005)

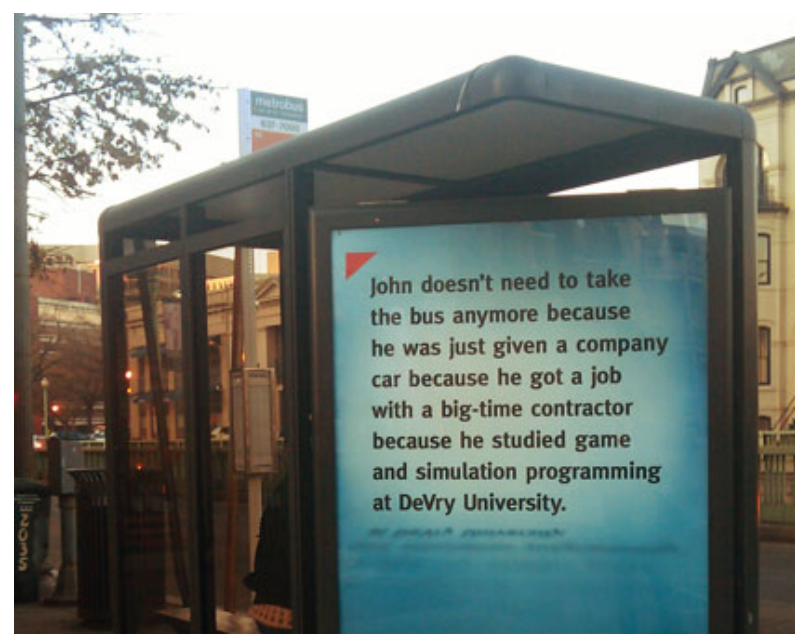

DeVry University advertisement (Murphy, 2013)

Figure 7: Examples of utilitarian transit brand expression

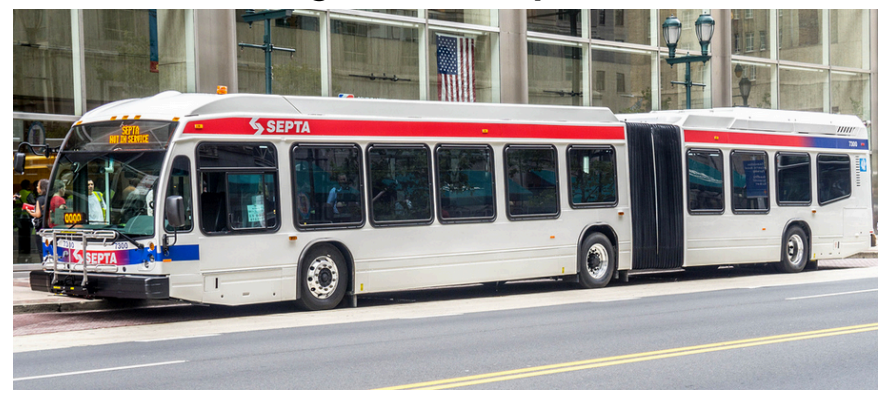

A SEPTA bus in Philadelphia (Stewart, 2013)

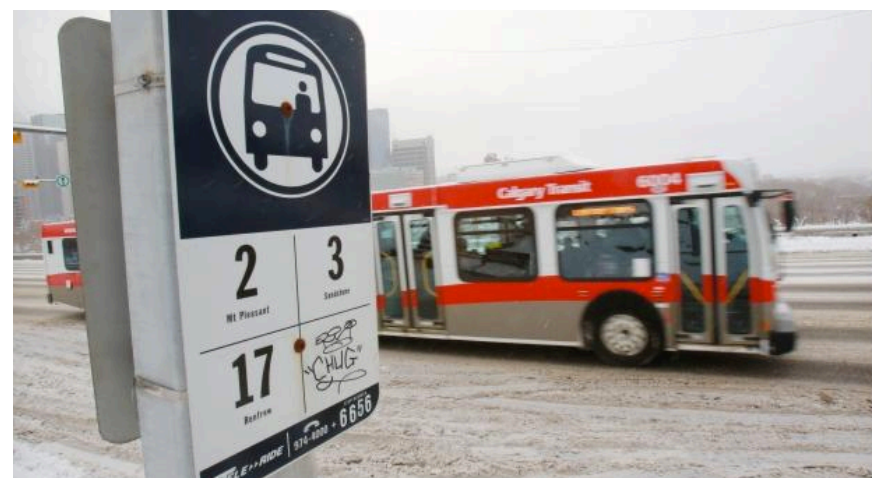

Calgary Transit bus and stop sign (Young, 2012)

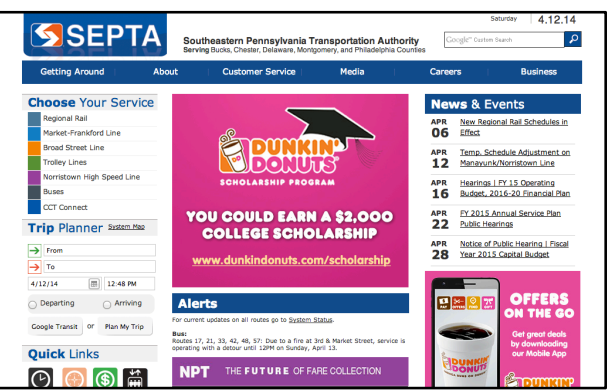

SEPTA website (www.septa.org)

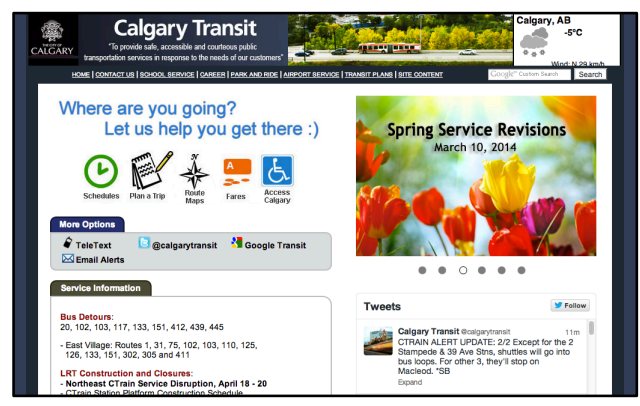

Calgary Transit website (www.calgarytransit.com) 
Figure 8: Examples of high-impact brand expression (Metro, Los Angeles County)

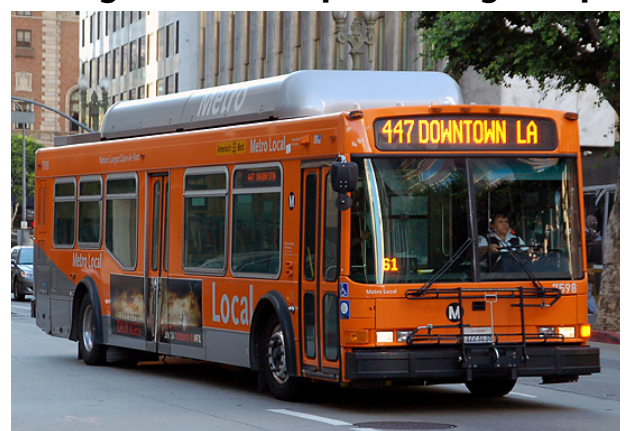

Metro Local, Los Angeles (McConnell, 2008a)

("The Port of Authority,"

http://www.cptdb.ca/wiki/index.php?title=File:Los_Angeles_Metro_7598-a.jpg)

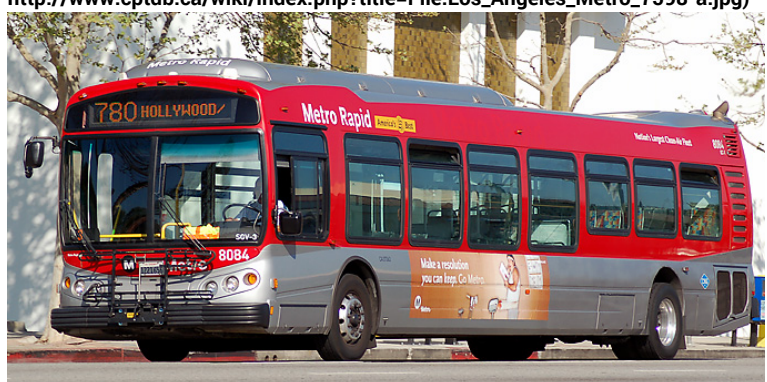

Metro Rapid, Los Angeles (McConnell, 2008c)

("The Port of Authority," 2008,

http://www.cptdb.ca/wiki/index.php?title=File:Los_Angeles_Metro_9368-a.jpg

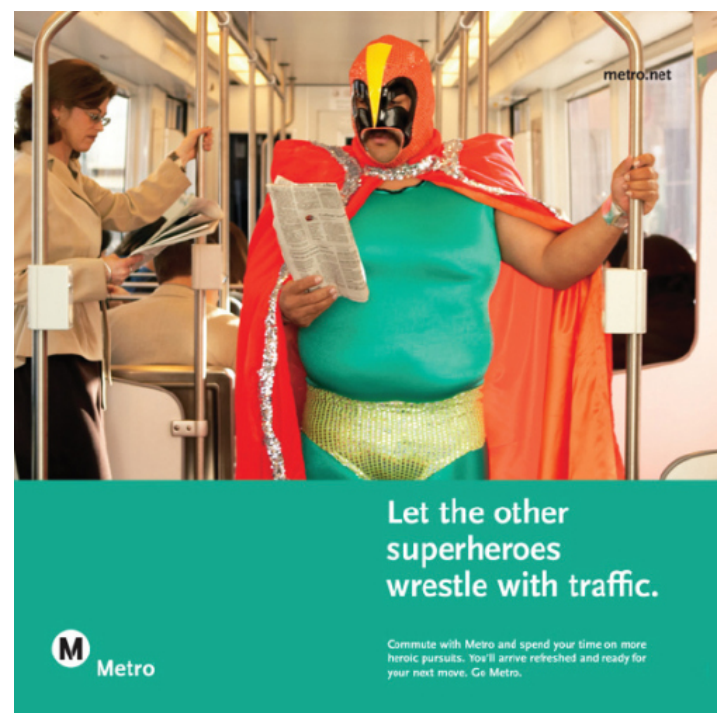

Advertisement produced by Metro Design Studio (from Arpi, 2009)

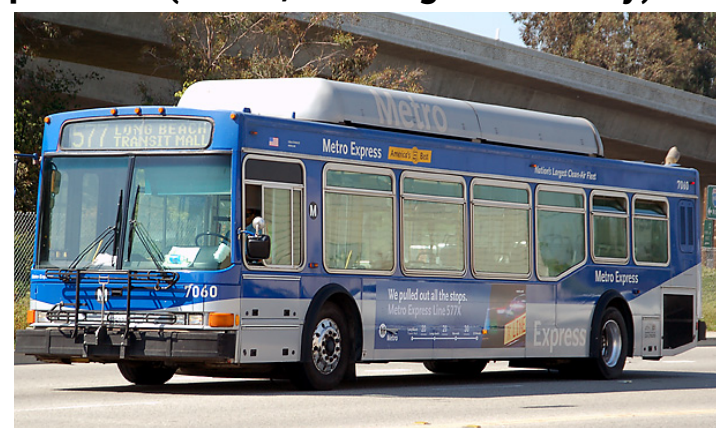

Metro Express, Los Angeles (McConnell, 2008b)

("The Port of Authority," http://en.wikipedia.org/wiki/File:Metro-Express577.jpg)

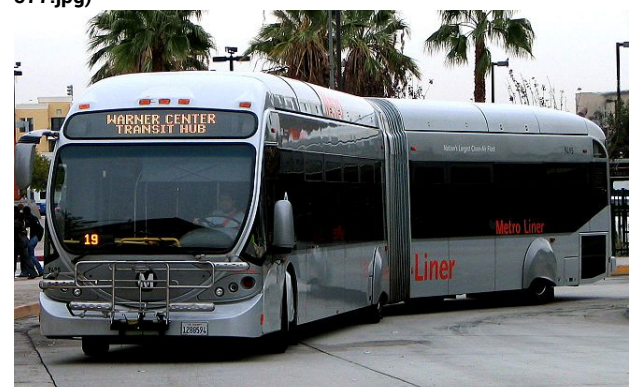

Metro Liner bus rapid transit vehicle, Los Angeles (Leung, 2010)

Leung, A. (2010),

http://www.cptdb.ca/wiki/index.php?title=File:Los_Angeles_Metro_9495. JPG)

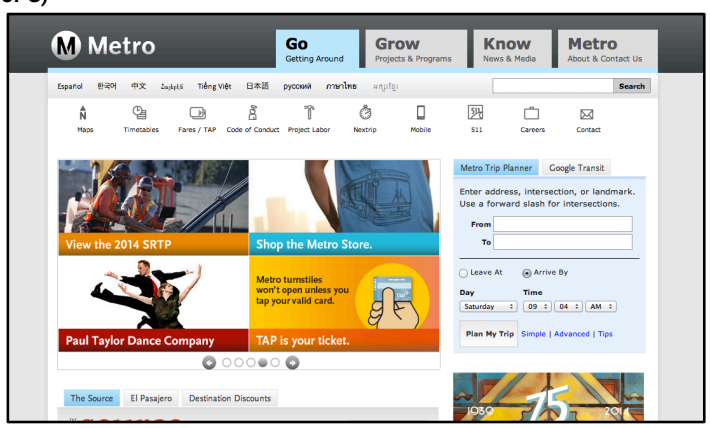

Metro website (www.metro.net)

The stylistic elements of transit brand image are somewhat subjective, but there appears to be compelling reasons to invest in brand image and marketing. 
As riders spend a majority of their time in transit vehicles, they are the primary touch-point with the transit brand. The livery and branding of transit vehicles performs a number of functions simultaneously. First, it reinforces to anyone on the street who sees the vehicle that a transit service runs on that street. In other words, even non-transit riders (those on foot, bicycles, or automobiles) are reminded that a service exists on that particular street (Walker, 2011a). Second, it is a sign that a new service has been launched and a new transit experience is available for potential riders (Cain, et al., 2009).

Due to underfunding, and the need to generate advertising revenue, most transit agencies have taken to not only placing ads on board, but also wrapping the vehicle with top-to-bottom advertising. This approach not only conceals and undermines the brand identity of the operating agency, but also can be used to advertise other travel modes that are in direct competition with transit, namely the automobile (Nordahl, 2009).

Websites, maps, timetables, signage, information posters, and social media are other avenues to engage with riders. Bus stop signs must be noticeable on the street, but also convey useful information to riders without overwhelming them. Maps are critical to assist riders who need to plan trips to unfamiliar areas. Guo (2011) found that riders rely on map information more than they trust their own memory, and that the design elements of route map have distinct implications for how riders plan their route. A number of agencies are adopting frequent network maps in order to simplify graphic representation and promote their services for which you don't need a timetable (a frequency better than 15 minutes, for example)(Walker, 2009).

It appears that the user-friendliness and brand image of transit are the focus of considerable investment for many agencies. As mentioned above, improvements in brand identity and wayfinding seem to have seen returns in ridership and revenue in the United Kingdom (Currie and Wallis, 2008). From a simple survey of various agencies' websites, one can easily see that the consideration of brand image is uneven across jurisdictions and transit agencies. Some have visual brands that are more pleasant than others, and some have easier to use website navigation schemes than others. If one assumes that resources are a constraint everywhere in transit, then why are some agencies making the case and investing time and effort in this area while others are not? 


\section{Branding and marketing}

Put simply, a brand is the "gut feeling" or emotional response triggered upon thinking of a company, product, or service. For example, if a company surveyed its customers on what they thought about the company, the most consistent themes in the feedback would be its brand (Webber, Arpi, and Carrigan, 2011). It is not the logo, which is part of the brand expression, but rather the reputation of the values and product offerings that the customer base has of the provider (Webber, Arpi, and Carrigan, 2011).

There are several reasons why a transit agency would be concerned with brand image and marketing. First, worldwide spending on advertising by auto manufacturers amounts to somewhere between $\$ 21$ billion US (2009 data from Webber, Arpi, and Carrigan, 2011) to \$40 billion US per year (Cain, et al., 2009). This is concerning as automobiles are the principal competitors to transit, and car manufacturers have successfully attached the automobile to lifestyle and self-image. For example, the type of vehicle purchased conveys the image the buyer wants to portray to others (Heffner, Turrentine, and Kurani, 2006).

The resources by transit on its image have not been enough to offset the emotional attachment of North Americans to motor vehicles. Negative images of transit are easy to come by, as most people surveyed associate transit (the bus in particular) with low income or mentally ill people, as a transport mode for others and not themselves, as unsafe due to the potential to victimized by crime, and as the last resort if one did not own a vehicle (Cain, et al., 2009). Some transit agencies have made considerable investments in brand image. VIVA in York Region, Ontario, implemented a bright and eye-catching brand identity system, which is implemented consistently across the board (vehicle livery, print materials, fare collection equipment, station design, etc.). This was a priority because bus rapid transit was selected as the mode for future transit improvements, and surveys revealed that York residents had a negative perception of the bus (Webber, Arpi, and Carrigan, 2011).

There are functional aspects to brand expression. Since the vehicles are the primary physical component of a transit system (Cain, et al, 2009), the design and styling of the vehicle can by a unique role in improving the image of transit.

The second functional aspect is wayfinding. On corridors where multiple types of services are overlaid (rapid service over a local service, for example), the colour of the approaching bus can help riders determine what service it is providing (Walker, 2013). For example, in Los Angeles, a 
red bus indicates it is a rapid service, orange a local, blue an express, and silver a bus rapid transit vehicle (see Figure 9).

A solid brand image is typically included as a critical component of bus rapid transit implementation. It is typically stated that the objective of the brand is to facilitate improved public perception of bus-based modes in comparison to rail, which is traditionally better perceived (Cain, et al., 2009). Further, the brand image unites all the elements of the service and emphasizes the unique features of BRT (Levinson, et al., 2003). What is not so clear is the rider response to investing in such efforts, and the justification of spending resources on something beyond a utilitarian image for transit.

Forsey, et al. (2012) found that the introduction of the VIVA bus rapid transit system in York Region, Ontario, played only a minor role in increasing post-secondary transit mode share. They could only speculate that the balance of the made share increase was due to the improved brand image of the VIVA service over the traditional service it replaced. In another example Metro in Los Angeles claims that their marketing and branding exercise in the mid-2000s was responsible for increasing the percentage of discretionary riders (those with other transportation options) as a portion of total ridership from 22 to 36 (Calderone, 2010). However, various service improvements such as the Metro Rapid network were implemented during the same timeframe. In summary, there appears to be anecdotal evidence and general agreement in the transit industry that investment in brand image is a good idea, but the quantitative evidence appears to be limited.

\subsection{4: Network design and physical elements}

\section{Network design}

One of the primary tasks in transit service planning is the alignment of routes, and in doing so service planners determine where to allocate resources (Nielsen, 2005). Some routes will inevitably be at one person's doorstep but far from another person's doorstep. A network design that minimizes transfers, but attempts to provide riders with one-seat rides, or near door-to-door service, emphasizes complexity. It also spreads the same amount of service hours across more routes, reducing frequencies and making the service less attractive (Walker, 2012). Conversely, a network design based on a grid, but which will require a transfer for most trips, emphasizes simplicity. In a grid network, service hours are concentrated on fewer routes, and frequencies can therefore be higher with the same operating budget (Nielsen, 2005; Walker, 2012; Mees, 2010; see Figure 9). High frequency of service is commonly accepted as the main element in making 
transit competitive to the car, namely in that it provides transit riders with any-point-to-any-point connectivity (Nielsen, 2005; Currie and Wallis, 2008).

Figure 9: Grid networks
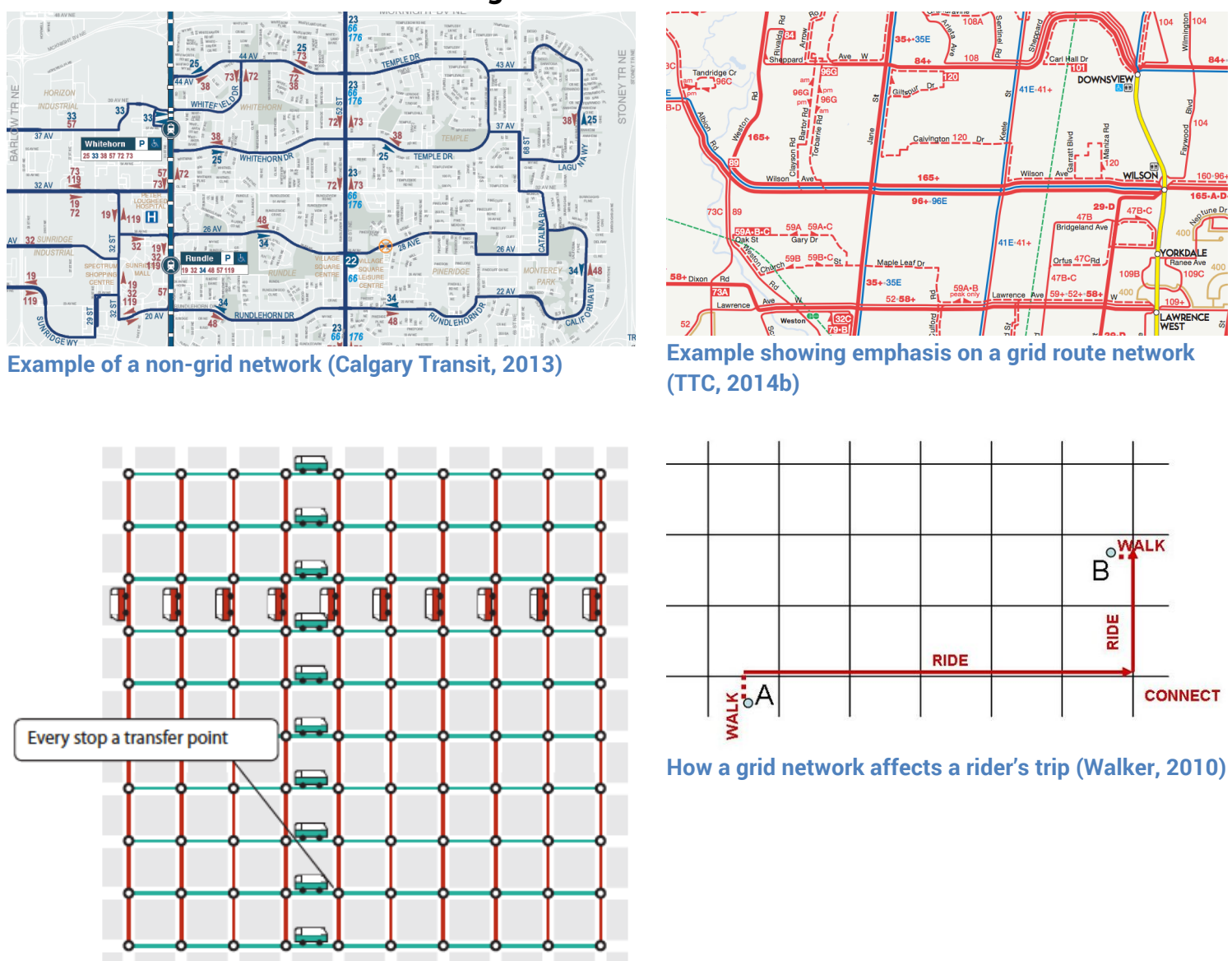

How a grid network affects a rider's trip (Walker, 2010)

Schematic of grid network (Nielsen, et al., 2005, 86)

\section{Fare collection}

In typical bus transit applications fares are collected when riders board transit vehicles. It is the role of the operator to ensure that fares are paid. The problem with this process is that riders can only board through the front door of the bus, instead of using all the doors. This amplifies the amount of time buses spend waiting at stops for riders to board and alight the vehicle, which is known as "dwell time." Excessive dwell time has been identified as one cause of poor bus route performance. For example, in New York City 22 percent of running time is spent dwelling at stops (Figure 10). 
Figure 10: Sources of delay for MTA New York City Transit buses (NYDOT/MTA, 2009a)

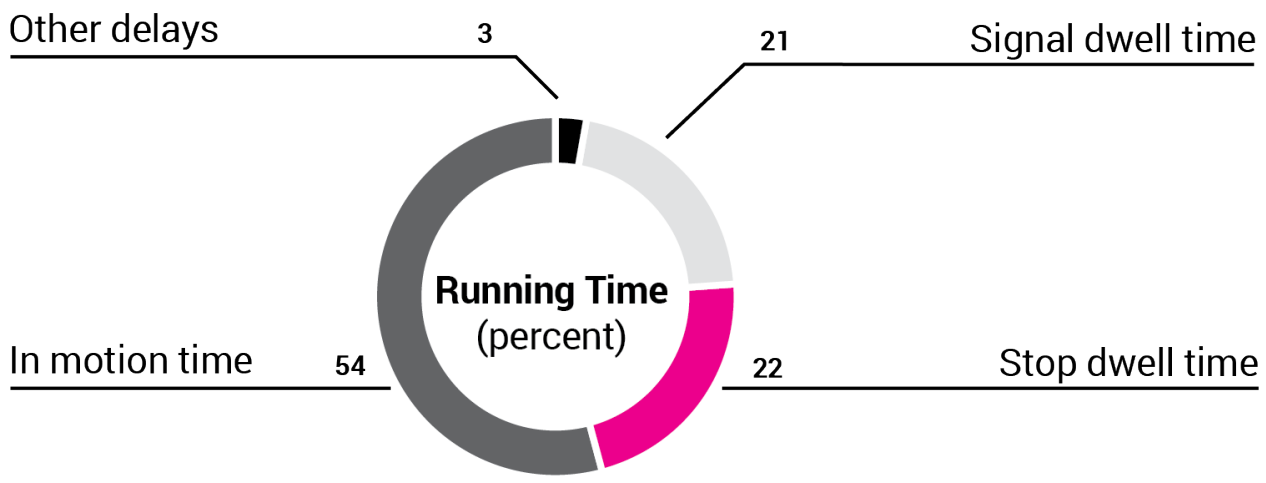

The main benefit of switching to faster fare payment processes is that it reduces the per-passenger time required to board the vehicle. Faster boarding methods include off-board fare collection (self-serve fare vending machines placed at each stop) and a proof-of-payment policy. An added benefit of getting fare collection done before the bus arrives is that it enables all-door boarding. Riders can use any door to get on or off the bus. On most articulated buses, this means that the available doors available for boarding increases from one to three (but the number of boarding "channels" increases from one to five or six, depending on the width of each door). Figure 10 shows how the per passenger boarding and alighting times decrease as the number of door channels increase (timings do not include fare payment).

Table 3: Boarding/alighting times (Danaher, et al., 2004)

\begin{tabular}{llll}
$\begin{array}{l}\text { Available Door } \\
\text { Channels }\end{array}$ & Boarding * & Default passenger service time (seconds/passenger) ** \\
\hline 1 & 2.5 & Alight (front door) & Alight rear door \\
\hline 2 & 1.5 & 3.3 & 2.1 \\
\hline 3 & 1.1 & 1.8 & 1.2 \\
\hline 4 & 0.9 & 1.5 & 0.9 \\
\hline 6 & 0.6 & 1.1 & 0.7 \\
\hline * Assumes no on-board fare payment required & 0.7 & 0.5 \\
** Increase boarding times by 20 percent when standees are present. For low-floor buses, reduce boarding times by 20 \\
percent, front alight times by 15 percent, and rear alighting times by 25 percent.
\end{tabular}




\section{Stop spacing}

Each stop provides access to bus service, but also adds to the travel time. This is consistent with Nielsen, et al., (2005) and Walker (2011b) who propose regular stop locations at the intersection of arterial roads (every mile/1600 metres), then two to three intermediate stops to service collector/arterial intersections.

Many transit agencies are conducting "stop rationalization" programs, in order to make bus services more efficient and increase speed and reliability (Spokane, 2014). Generally, the objective is to increase stop distances to a predetermined, published, and agreed-upon standard. Alternatively, stops can be moved, rather than removed, to better serve major activity centres or vulnerable groups.

\subsection{5: Comfort, convenience, safety, and waiting}

Various intangible factors influence riders' perception of transit and the willingness of discretionary riders to select transit as a preferred travel mode. The influencing economic factors in mode choice selection are generally accepted to be cost in money, cost in time, and comfort/convenience (Bertaud, Lefèvre, and Yuen, 2011). The question pertinent to a transit planner is: which factor should be prioritized first?

The monetary cost in selecting travel modes is the subject of substantial investigation. Discussing the cost factor entails discussions of appropriate fares, incentives, congestion pricing, marginal cost pricing, etc. (Vuchic, 1999; Newman and Kenworthy, 1999; Kitchen, 2002; Bertaud, Lefèvre, and Yuen, 2011), issues that often go beyond the jurisdiction of a transit agency. However, the cost in time has been frequently shown to be more valuable to users of transportation networks and has more of an influence on luring discretionary riders (Mees, 2010; Currie and Wallis, 2008; Litman, 2013). This is why it is generally agreed that the first priority for improvements is the frequency and reliability of transit services to enable greater freedom for discretionary riders and minimize wait times. Other priorities are also time savers such as increasing the overall speed of a trip by separated guideways, signal priority, reducing dwell times, etc. (Currie and Wallis, 2008; Currie and Delbosc, 2013).

Planners of the rapid bus systems mentioned above prioritized the design of vehicles and other physical attributes such as upgraded stops and shelters, real time information displays, etc., indicating a particular concern for luring discretionary riders by improving rider comfort (Cain, et al., 2009; Pessaro, et al., 2011). In a survey of female transit riders who were also recent 
immigrants to the Toronto area, Lau (2007) noted that, in addition to cultural and language barriers, the physical challenges of attempting to bring strollers and groceries onto crowded Toronto buses were a major detractor from transit use. Transit buses, even articulated (18 metre) versions, are much narrower than most light rail and heavy rail vehicles (Vuchic, 2007).

The users' perspective, according to research, tends to place less emphasis on comfort factors and more emphasis on the practical aspects. For example, Yoh, et al. (2010) suggests that when it comes to amenities at stops and stations, personal safety (particularly with regard to the surrounding environment) is the most important factor to riders. Service reliability and frequency follows, then accessibility of stops and provision of information, and finally amenities. This forms a strata that somewhat mimics Maslow's Hierarchy of Needs (see Figure 11).

\section{Figure 11: The hierarchy of transit needs (Yoh, et al., 2010)}

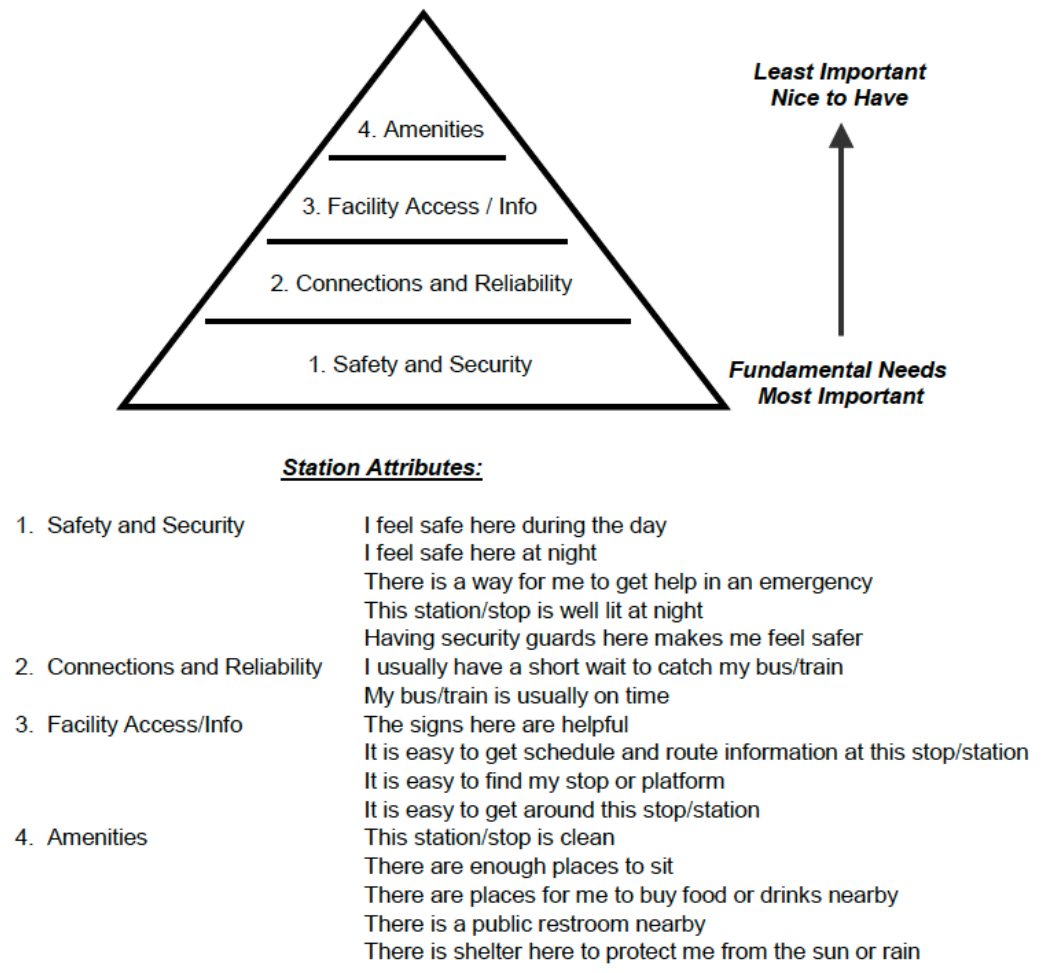

The final factor in influencing the attractiveness of transit is waiting. As Li (2003) notes, we hate to wait. Transit is at a distinct disadvantage in comparison to the automobile. This is due to the dilation of perceived time, which varies depending on the situation. For example, even though a motorist may be facing a long commute their mind tends to be occupied, so the perceived time passed is less than a transit rider who is waiting at a bus stop with no idea of when the bus will arrive. In that situation the perceived time penalty (which lengthens the perceived trip time by 
transit and the frustration of the rider) is the highest. The effect of real time information systems, showing when the next few trips are expected to depart, has been shown to greatly reduce the perceived wait time for transit riders, in many cases by up to 20 percent (Litman, 2013).

As the primary mode of providing transit services in North America, the transit bus is ubiquitous, but not well liked. It has a poor public image, and is largely viewed by discretionary riders as the transport mode for "others, but not me." Further, there is evidence to suggest that even captive riders, those who would benefit most from fast and effective rapid transit, are not being served. Socio economic and spatial changes to North American cities have caused a substantial mismatch between service and market. The bus is inexpensive, and new modes of thinking about planning bus transit service, such as rapid bus systems, are being developed and deployed on city streets in Canada and the United States. What is the planner's role in addressing these challenges? What do the mechanics of implementation look like, in addition to the mechanics of service provision and technology? Since transportation is an urban sustainability issue, looking at what prevents progress in addressing sustainability issues may shed light on barriers to implementation.

\section{3: What is preventing progress?}

Three latent effects characterize the barriers to mode shift towards public transit. The first is the changes in metropolitan morphology during the automobile era. The second is delayed implementation due to a lack of revenue and insufficient capital budgets. Finally, the traditional models of public administration are preventing horizontal and integrated decision-making processes necessary in order to address sustainability challenges.

\subsection{1: Spatial mismatch of rapid transit service and transit-dependent people}

The character of urban morphology of North American cities has shifted gradually since the 1950s from a monocentric format (a dominant central business district [CBD] surrounded by residential sectors) to a polycentric format (dispersion of various uses throughout the region). Where previously a typical "radial" commute from a streetcar suburb to a CBD could most efficiently be served by transit, dispersion and suburban sprawl has reinforced an anywhere-toanywhere travel pattern that is difficult to serve using traditional radial transit networks (Newman and Kenworthy, 1999; Hemily, 2004; Amin, et al., 2013; Bertaud, Lefèvre, and Yuen, 2011).

Transit services, particularly in terms of high frequency and reliable rapid transit lines, are now dislocated from activity and employment centres, which have emerged in the suburbanized modern metropolis. Consequently public transit is unable to provide an effective transportation 
option to the very people who rely on it the most. This further reinforces dependence on automobiles and reduced access to employment due to the sheer distance and time needed to commute by transit. The very people who can least afford to buy and maintain a car are thus compelled to purchase and maintain one in order get from home to work (Tomer, 2011; Tomer, Kneebone, Puentes and Berube, 2011).

In contrast, high skilled jobs have remained concentrated in the urban core where rapid transit tends to be focused. However, it is the dispersed employment areas that provide work opportunities for low-skill workers, yet they are difficult to reach (Tomer, Kneebone, Puentes and Berube, 2011). An accute example of this pattern has emerged in Toronto, which will be explored below.

\section{Spatial mismatch in Toronto ${ }^{4}$}

The spatial mismatch of rapid public transit and the people who rely on transit the most lies at the intersection of several ongoing economic and social forces. Urban planning, social, and economic researchers have been uncovering the dynamics of these issues, and how they influence each other.

Since the mid-1970s, immigrant settlement has been concentrated in the suburban perimeter of Toronto (Hulchanski, et al., 2010). Recent and established immigrants are finding it difficult to find living wage employment (United Way Toronto, 2012).

These factors have spatially polarized incomes into the "three cities within Toronto" (Hulchanski, et al., 2010):

- An upper-income city in the gentrified urban core (first city)

- A low-income city in the outer suburban perimeter which sees higher concentrations of low incomes, recent immigrants, and people of colour (third city)

- And a diminishing second city, primarily comprised of the earlier generation of immigrants to Toronto (Hulchanski, et al., 2010)

\footnotetext{
${ }^{4}$ The author has previously explored the issue of spatial mismatch in Toronto in an unpublished academic paper (Sadoway, 2012). This section largely reiterates and expands on that work.
} 
Figure 12: Three cities in Toronto (Hulchanski, et al., 2010)

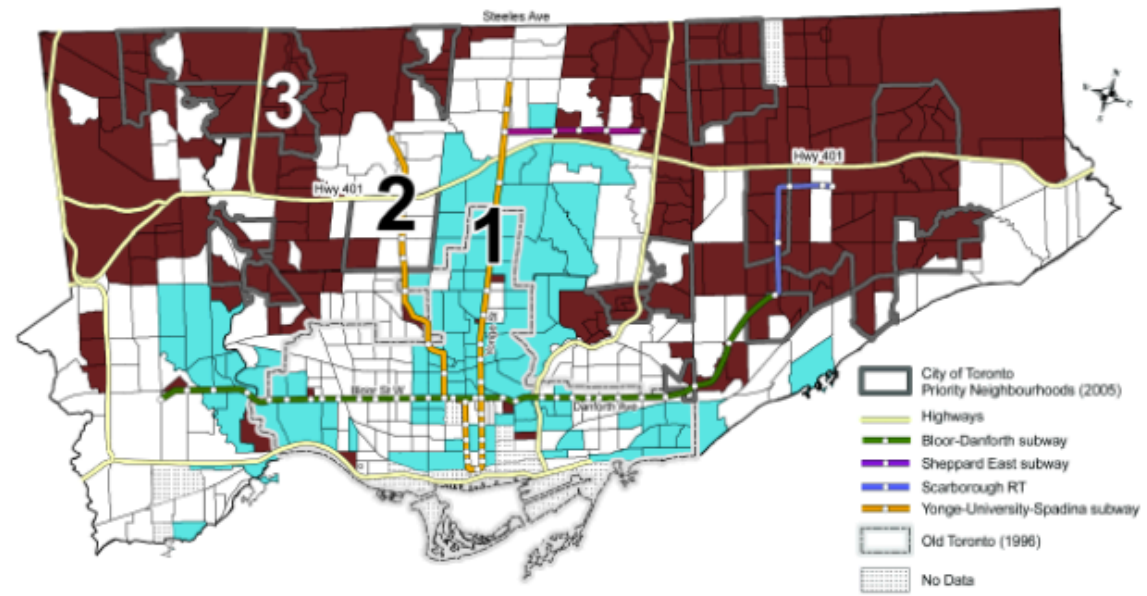

Change in the Census Tract Average Individual Income as a Percentage of the Toronto CMA Average, 1970-2005

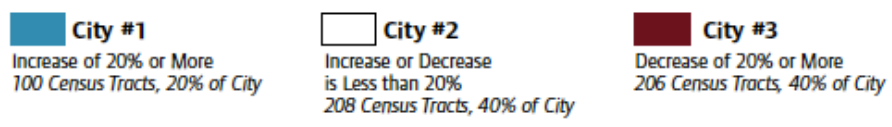

The three cities are also further striated by economic class. The transition to the globalized knowledge economy has resulted in a reduction of workers in the working class in favour of a sharp increase in the service class. In Figure 13, Adler, Bednar, and Matheson (2010) show how creative class occupations are generally found in the first city (in areas well served by rapid transit). Conversely, working class occupations are concentrated in the third city areas, with little access to rapid transit, and the service class is somewhat dispersed throughout.

Figure 13: Creative class share of total occupations (Adler, Bednar, and Matheson, 2010)

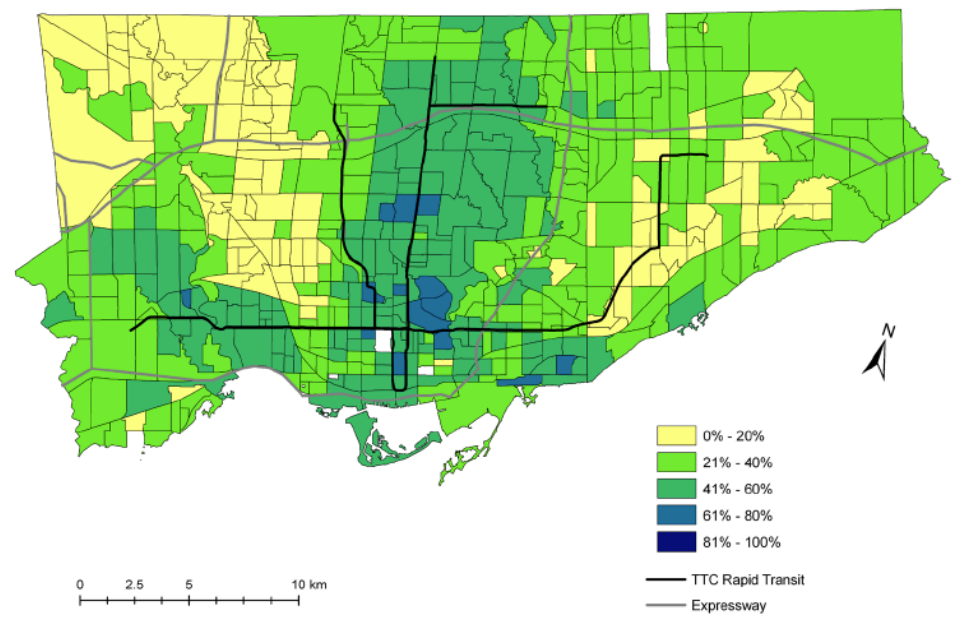


The mismatch problem extends beyond geographic location into the realm of built form, and eventually, sense of place. Recent immigrants and people with low-incomes have made their homes in clusters of aging high-rise towers, which were built in car-centric suburban contexts (Hulchanski, 2007; Stewart and Thorne, 2010; Stewart, et al., 2012; United Way Toronto, 2012). This situation presents considerable challenges for marginalized communities seeking transportation by active modes or public transit. Hess and Farrow (2011) conducted a series of surveys and focus groups with the residents of several tower neighbourhoods, which revealed the following:

- The walking environment surrounding several of these low-income tower clusters can be hostile and intimidating to pedestrians.

- 41 percent of the survey residents used transit to get to work, while 16 percent walked.

- People walking to services or transit stops had to cross wide high-speed arterial roadways or shortcut through holes in chain link fences to reduce the circuitous walking distances.

- When asked if they were saving to purchase a vehicle, a majority of participants responded that they were.

This suggests that, due to the inconvenience of walking and using public transit and the lack of a comfortable pedestrian realm, saving for a car is the top priority for many tower cluster residents, despite lower incomes and high-density living arrangements.

A look at transit commuting itself reveals a similar story. Trips by suburban low-income income transit commuters are long and exhausting. They are frequently by bus in mixed traffic, which makes travel times unpredictable due to overcrowding and unreliable service (Grewal, 2006). The Martin Prosperity Institute (2011) has created compelling visual evidence of "transit deserts" within Toronto (areas of sparse local bus service and an absence of rapid transit service), which align with the third city (Figure 14). 


\section{Figure 14: Rapid transit service gaps and the third city (Map by Matheson, Z., from Martin Prosperity Institute, 2012)}

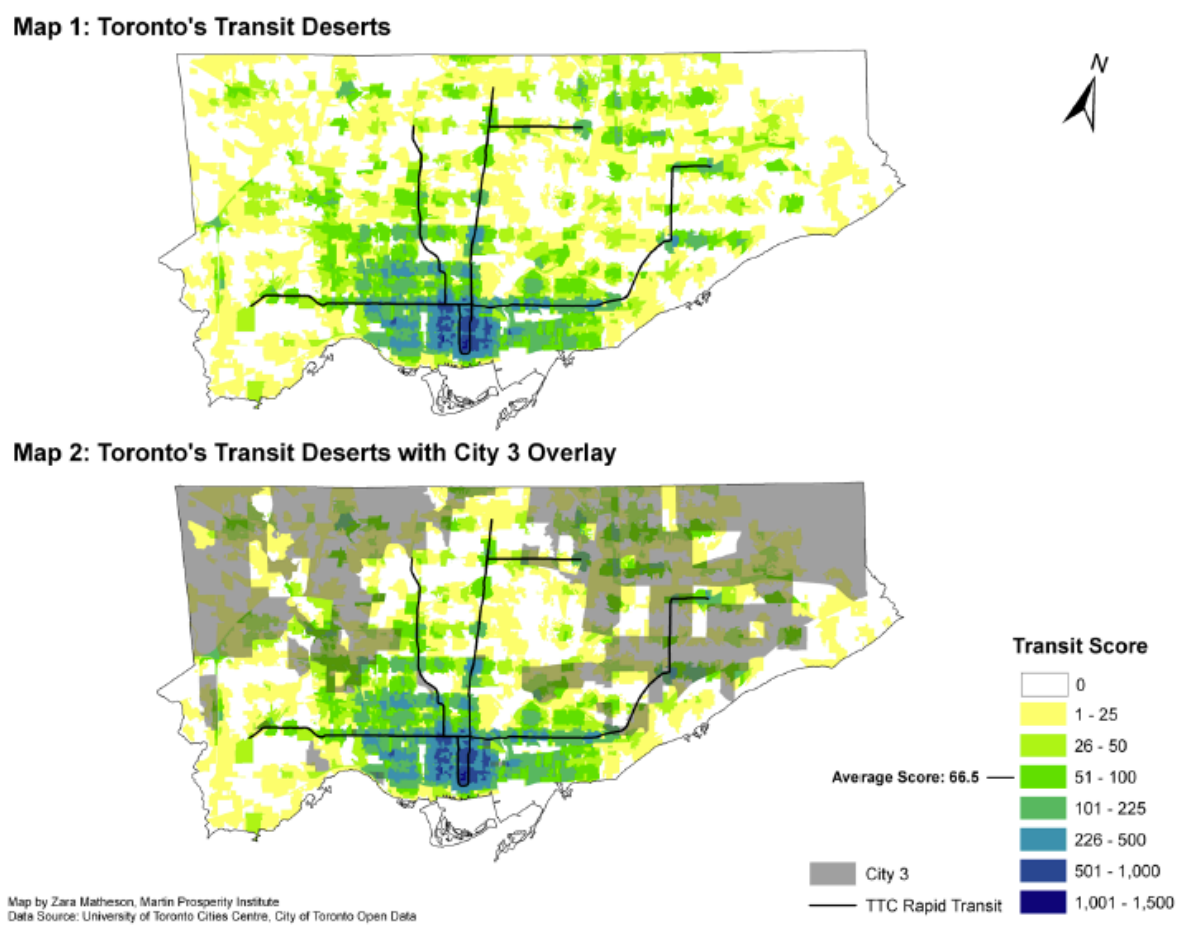

One of the most significant planning and public policy initiatives that would have attempted to address the spatial mismatch was the Transit City Light Rail Plan and the accompanying Transit City Bus Plan (Figure 15). The intent of Transit City was to extend light rail rapid transit and express bus routes into Toronto's western, northern, and eastern suburbs (the areas shaded in grey in Figure 14), which are currently underserved by rapid public transit (TTC, 2007 and TTC, 2009, see Figure 15).

The Transit City LRT plan was formally cancelled in 2010, despite the planned addition of light rail and express bus services in the inner suburban third city to improve reliability and reduce trip times. Despite this, construction of the Eglinton Crosstown line is underway at the time of this writing, and the Sheppard and Finch West LRT lines remain part of the Metrolinx "Big Move" transit strategy. Further, the TTC has continued to implement the Transit City Bus Plan by making operational changes such as the addition of the 195 Jane Rocket on March 30, 2014 to provide express service on Jane Street from Bloor Street to Steeles Avenue (TTC, 2014a). 


\section{Figure 15: The Transit City plans}

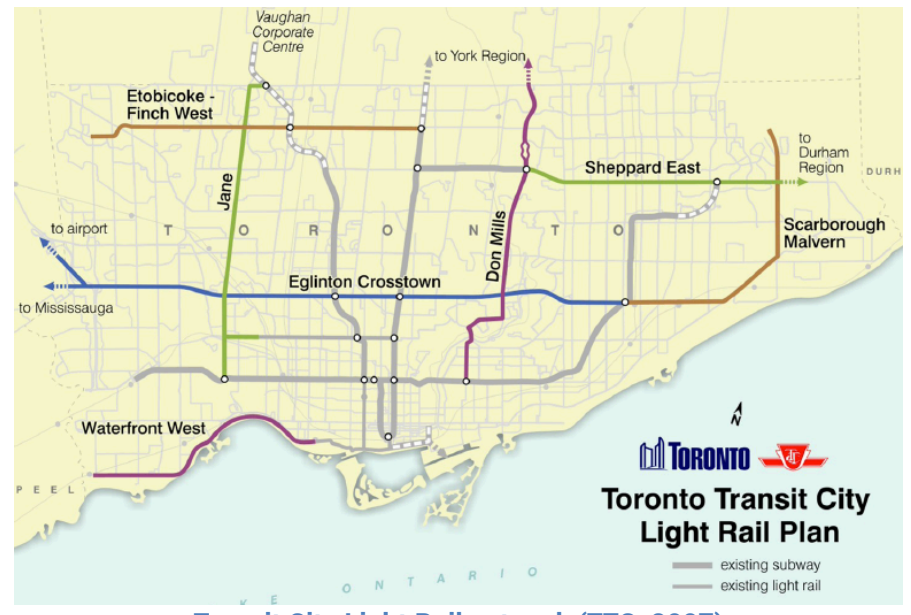

Transit City Light Rail network (TTC, 2007)

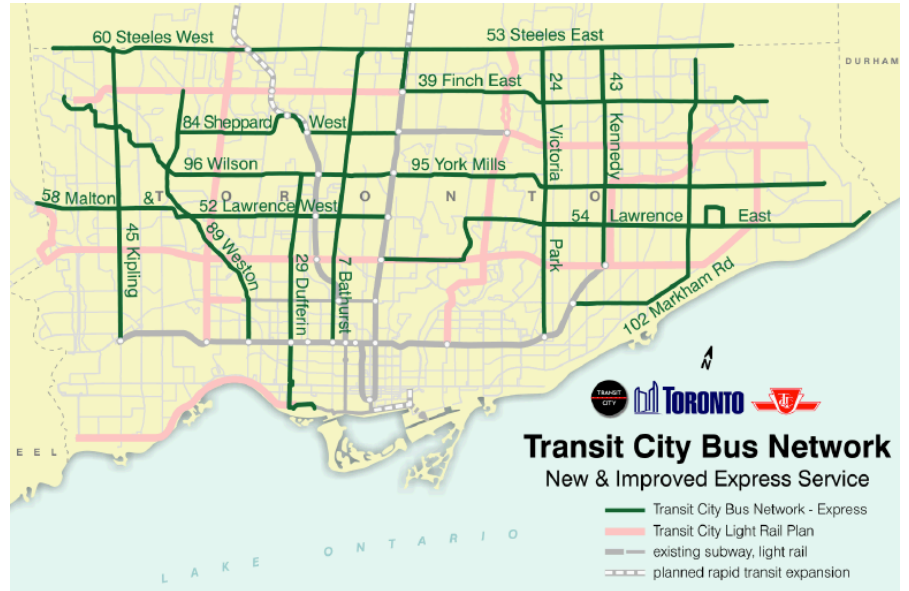

Filling in the gaps. Transit City express bus network (TTC, 2009)

\subsection{2: Funding and financing transit needs ${ }^{5}$}

To address travel behaviour change to public transit to reduce emissions and energy consumption, and to address the spatial mismatch dimension of adapting transit services to a new suburban morphology, substantial public investments are required. Despite recent investments in public transit (bus rapid transit systems in South America and Southeast Asia, for example) transportation investment in developing countries is still dominated by automobile infrastructure (Amin, et al., 2013). This is also a Canada-wide issue, and cuts across taxation policy and the division of powers between different levels of government (Roschlau, 2007). In its National Transit Strategy, the Federation of Canadian Municipalities (2007) identified a public infrastructure gap in Canada of $\$ 20.7$ billion, in terms of renewal of existing infrastructure and

\footnotetext{
${ }^{5}$ The author has previously explored the issue of transit funding in an unpublished academic paper (Sadoway, 2013). This section reviews and expands on that material.
} 
new investments to meet increasing demand. The strategy also identifies the need for a $\$ 4$ billion per year dedicated funding stream.

Replacing aging municipal infrastructure and the selection of rapid transit alternatives designed to attract people from automobile travel are the topic of numerous debates with the political sphere and public discourse. In Toronto, for example, public transit is one of the primary issues of the 2014 mayoral election (Ratchford, 2014).

The problems with access to rapid transit are being compounded by transit's increasing popularity. To address climate challenges and resource scarcity, cities are compelled to reinvest in transit at the precise time they face calls for restraint on public expenditure along with an uncertain global economy. At the same time transit ridership figures are up in major North American cities (APTA, 2013; CUTA, 2013 [see Figure 16]) and there is a renewed interest, particularly by the millennial generation, in urban transit-dependent living arrangements (Sakaria and Stehfest, 2013).

Per capita ridership in Canada's largest cities has been increasing since the mid-2000s (Figure 16). Existing services in the largest metro areas, such as Toronto, have become overcrowded as agencies struggle to meet demand with existing infrastructure and operating funds (FCM, 2007). This has a significant impact in terms of ensuring mobility and access for those currently using transit, as well as for attracting discretionary riders to transit.

Figure 16: Transit ridership in Canada, 2008 to 2012 (CUTA, 2013)
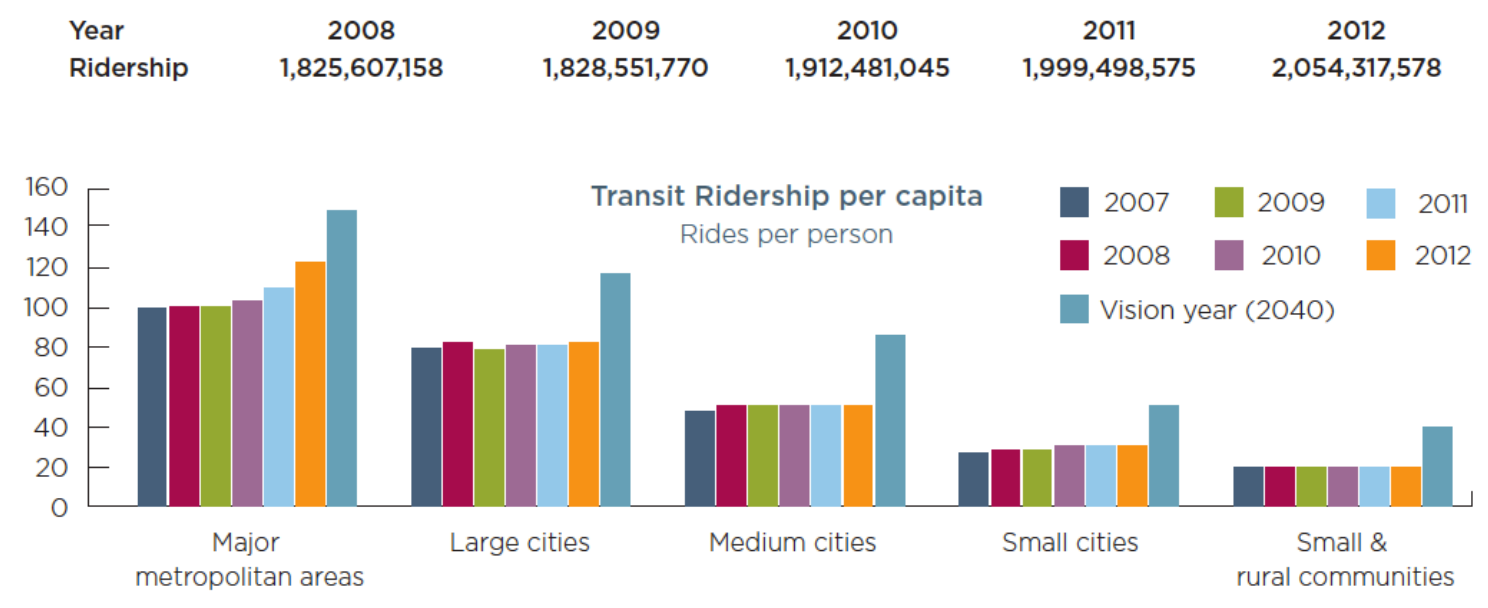


\subsection{3: The silo mentality and unsustainable modes of thinking}

Improving transit capital infrastructure involves large project teams made up of professionals from various disciplines from numerous departments and agencies, each responsible for its own set services and priorities. Through researching various examples of bus transit system improvements in Canada and the United States, the various actors and their responsibilities were captured and are summarized below (Table 4). This is by no means an exhaustive list, and local circumstances will determine the actors involved, but it does point to inherent complexity and interdisciplinarity of work in the transit industry.

\section{Table 4: Who does what in transit projects}

\begin{tabular}{|c|c|}
\hline Project Phase/Component & Actor \\
\hline $\begin{array}{l}\text { Long range transportation planning, network } \\
\text { and corridor planning }\end{array}$ & $\begin{array}{l}\text { Metro Planning Agency } \\
\text { Department of Transportation } \\
\text { State and/or Local Transportation Planning Dept. } \\
\text { Transit Agency (Service Planning Dept.) } \\
\text { Private Consultant }\end{array}$ \\
\hline Public engagement & $\begin{array}{l}\text { Metro Planning Agency } \\
\text { State and/or Local Transportation Planning Dept. } \\
\text { Transit Agency (Service Planning Dept.) } \\
\text { Private Consultant }\end{array}$ \\
\hline Capital financing & $\begin{array}{l}\text { Federal Transit Administration or Treasury Board } \\
\text { Metro Planning Agency } \\
\text { State/provincial and local government }\end{array}$ \\
\hline Operating financing & $\begin{array}{l}\text { Federal Transit Administration } \\
\text { State/provincial and local government }\end{array}$ \\
\hline $\begin{array}{l}\text { Guideway design, bus lanes, and other } \\
\text { geometric changes }\end{array}$ & $\begin{array}{l}\text { Department of Transportation } \\
\text { Private Consultant } \\
\text { Transportation Services Dept. (roadway construction and maintenance) }\end{array}$ \\
\hline Transit priority signals & $\begin{array}{l}\text { Department of Transportation } \\
\text { Transportation Services Dept. (roadway construction and maintenance) } \\
\text { Fleet Services Dept. (vehicle hardware) }\end{array}$ \\
\hline Service operational plan & $\begin{array}{l}\text { Metro Planning Agency } \\
\text { Transit Agency (Service Planning Dept.) }\end{array}$ \\
\hline Station stop design and installation & $\begin{array}{l}\text { Transit Agency (Marketing and Communications Unit+ } \\
\text { Private Consultant } \\
\text { Transportation Services Dept. (installation) }\end{array}$ \\
\hline Vehicle purchasing and brand livery & $\begin{array}{l}\text { Transit Agency (Marketing and Communications Unit) } \\
\text { Fleet Services Dept. } \\
\text { Transit Agency }\end{array}$ \\
\hline Brand identity and marketing strategy & $\begin{array}{l}\text { Transit Agency (Marketing and Communications Unit) } \\
\text { Private Consultant }\end{array}$ \\
\hline Capital maintenance & $\begin{array}{l}\text { Transit Agency } \\
\text { Transportation Services Dept. (roadway construction and maintenance) } \\
\text { Fleet Services Dept. (vehicle maintenance) }\end{array}$ \\
\hline Ongoing evaluation and monitoring & $\begin{array}{l}\text { Transit Agency } \\
\text { Industry associations (APTA/CUTA) } \\
\text { Academic researchers }\end{array}$ \\
\hline
\end{tabular}

Given the severe challenge of curbing GHG emissions to avoid severe climate effects, the impacts of spatial mismatch and suburban morphology, and the poor public image of public 
transit (and the bus in particular) what is preventing movement in addressing these problems, and improving bus transit? One answer might be in the nature of the problems themselves. Sustainability issues tend to be broad, multivariate, complex, and dynamic. They are not static and narrow. Yet our governance and decision-making structures are only best equipped to handle static and narrow problems.

In Chapter 7 of At the Edge (2001), Ann Dale asks the question of why after decades of common agreement among the scientific community, and even political direction to address sustainability challenges, we still have not made the shift in thinking and behaviour necessary to avoid exceeding ecological carrying capacity. Based on her experiences in the Canadian federal civil service she arrives at a number of conclusions, such as that the structure and ordering of our bureaucracies was created during an outmoded paradigm: the early industrial extraction and export economy (Dale, 2001, 99). These bureaucratic departments have priorities and missions in direct conflict with each other.

Dale cites an example in the Canadian federal government where interdepartmental disagreement was hampering efforts to deal with identifying toxic substances (Dale, 2001, 110). These departments are effectively "siloed," that is, each discipline, department, or agency, focuses inward, and sets priorities and working methods according to the dominant profession. Their internal culture prevents not only recognition and comprehension of sustainability challenges, but also the development of a coherent response to these issues (Dale, 2001, 97). This further gridlocks our political process and the public service, preventing necessary conversations from happening and changes from taking place:

" $[\mathrm{I}] \mathrm{n}$ the absence of a guiding framework and clearly articulated principles for operating across departments, gridlock appears ... to be eminently rational. This explains why, on the one hand, you can hand a department mandated to protect the environment and, on the other, one that actively supports unlimited industrial expansion (Dale, 2001, 102).

Furthermore, the analytical and decision-making processes commonly used by public services tend to adopt a scientific rationality: the categorization, dissection, and compartmentalization of problems. The compartmentalization of the professions (planners, public administration, engineering, etc.) can effectively work against attempts at making decisions and planning in a comprehensive and holistic fashion (Dale, 2001, 106). It also prevents the use of emergent and creative solutions based on intuition and compassion. 
If we need to cut across disciplinary and organizational divisions to fundamentally re-envision our approaches to planning and designing urban systems to encourage sustainable development and adaptation, how can this be accomplished? What would a planner need to know to engage in interdisciplinary approaches? 


\section{3: Research method}

Since we are confronted with substantial urban sustainability issues, urban mobility issues, and a dominant transit vehicle technology that is not seen as attractive, this research project was directed at finding realistic and short-term improvements. The intent is also to reveal what it would take to get there, from the viewpoint of an urban planning student entering the field of transit planning. The following questions were used to uncover possible directions to the above findings:

- How can bus transit be positioned as a credible and attractive alternative to the automobile?

- What overall strategies appear to be the most successful?

- To what degree were new approaches sought in working with other disciplines and the public?

To begin the investigation, secondary literature review was conducted in order to diagnose the "problem" of bus transit and its image. This data was used to inform section 2.

The next step was to capture the story behind implementation of various forms of bus transit systems, and the current challenge of making bus transit attractive to potential riders.

Occupational field research (also known as a key informant interview) was selected as the mode of primary data gathering. This type of field research provides for the opportunity to establish a rapport with the participant, and uncover the personal insights informed by the experience of the participant and their professional history, in addition to the logistical detail (Neuman, 2011). The goal was not to catalogue the technical details behind implementation or seek a representative survey. Rather, the purpose was to review the approach used - what was successful, what was not, etc. The results of the interviews serve to support or oppose the findings from secondary research.

To recruit interview participants, five agencies were shortlisted based on the following criteria:

1. Similar (but not the same) operating characteristics to Toronto's urban bus transit services. For example, frequent service on major corridors (every 15 minutes or less).

2. Route alignments in a network grid approach such as that of Toronto, or a different approach (such as hub-and-spoke, minimizing transfers, etc.)

3. Recently implemented a rapid bus transit system or have considered such a service in the recent past. 
Eight practitioners who work in the transit industry in Canada were interviewed in February and March 2014 on their perspectives and insights on the issue of bus transit. The practitioners themselves are characterized by the following, which were based on the "Ideal Field Research Informant" criteria set out by Neuman $(2011,454)$ :

1. They occupy leadership positions or significant management roles in the planning and implementation of bus transit programs, and have much of the long-term institutional memory behind such projects

2. They may not be planners per se, but may also be from related professions: engineering, social research, marketing, etc.

The identity of the interview participants must remain confidential to satisfy requirements under the Tri-Council Policy Statement: Ethical Conduct for Research Involving Humans. The participants were engaged by telephone or in person conversation. The research used the following interview guide to direct the flow of the conversation, however discretion was used in the event a participant offered a new and intriguing line of inquiry. Comments by the participants were transcribed by the author and reviewed for common themes and disagreement. Frequency of similar responses was used to indicate agreement or disagreement on a certain point.

\section{Table 5: Interview questions}

- Please explain your role in this project?

- What about this service is working best? What is not working so well, or presenting an ongoing challenge?

- What helped get it started? How did it get past political, financial, and inter-agency "hang-ups" along the way?

- How was the public engaged in the planning and design process?

- If they were, what issues were encountered in public engagement?

- Is it the role of a transit planner to consider and advocate for the implementation of a cohesive brand identity, marketing and communications, and other methods to improve the image of bus transit? 


\section{4: Key findings}

The results of the key informant interviews conducted for this research paper are reported in this section. Most interview participants agreed that improving brand image was important to improving bus transit. Some participants were facing barriers to improving a bus network, while others were associated with rapid bus projects currently underway. The most frequently mentioned barriers preventing progress was the lack of financial resources and the misalignment of priorities between administrative agencies and departments.

The volume of comments was weighted towards the technical aspects of planning transit operations (referred to here as the "mechanics of bus transit"). While participants did note some advantages of rapid bus systems, they tended to return to the limitations or trade-offs associated with the bus, such as capacity limitations, the challenge in acquiring useful performance data, limited street width available for bus lanes and other transit priority measures.

One participant who had been involved over the course of a large-scale rapid bus project emphasized certain topics that others did not, namely the degree to which the public is actively engaged in the planning process, the planner's focus on meaningful improvements for transit riders, and how those improvements would be implemented. The more that transit planning agency actively engaged and communicated with the public, noted the informant, the better the process and outcome.

To simplify analysis and to facilitate drawing conclusions, the findings have been categorized as follows:

- Rethinking the approach to planning bus systems involves addressing the image of transit, steering progress towards addressing urban sustainability issues and spatial mismatch, and actively engaging the public.

- Rethinking the mechanics of bus transit to make progress achievable and get more people moving with limited public resources. Emergent service types such as rapid bus and network redesign hold promise. 


\section{1: Rethinking our approach to bus transit planning}

\subsection{1: Working across disciplines and departments}

Several interview participants noted that implementing a bus rapid transit project takes tremendous interdepartmental and cross-jurisdictional effort. Transit planners must work with other professionals who are certified to practice in their own field. If there are misalignments in vision and objectives, this can hold up progress or stop it altogether. Several participants agreed that planners should have the ability to work across disciplines. This is not to the extent that a planner positions themself as technically competent as a traffic engineer or a marketing/brand image consultant, but that the planner can "speak the lingo" and comprehend the fundamental concepts, tensions, and issues within each related profession. There is one reason why this is critical: implementation. Planners, as one participant noted, tend to write plans that are "highlevel" and sit on shelves "collecting dust." Interacting constructively with other disciplines helps planners to determine the practical components necessary to ensure the plan is implemented.

Working with other disciplines can result in a conflict of values and priorities. One participant noted that physical changes to signalling and street layout requires the involvement of the department of transportation or roadway operations department. Moving curbs to create transit priority devices such as queue jumps, the informant noted, is a proven method of improving reliability, but the lack of shared vision with both the transportation and urban design departments prevented installation. The transportation department may not share the same values of transit priority that service planners have. Their mindset may be about moving cars. Urban design teams are concerned about widening roads, the pedestrian realm, and crossing distances. Another participant commented on design, noting that good transit network design relies on good neighbourhood design. It is impossible to align a straight transit route if new neighbourhoods are designed and approved with disjointed collector roads.

Change in leadership at both the transit operating agency and the transportation planning agency provided an opportunity for one informant to begin the implementation of a rapid bus project. $\mathrm{He}$ outlined that the new senior leaders were looking for projects to kick-start and set the agenda for their term. In fact, he continued, it was useful to get to know new staff in any transportationrelated department to identify common interests. Indeed, there was agreement among most participants that having the "right people in the right place at the right time" was instrumental for momentum, and encountering "wrong people at the right time" could halt progress completely. 
Regarding addressing the image of transit, one participant said it takes tremendous coordination between service planning, marketing, fleet management, and bus operations departments in order to implement rapid bus systems with the characteristics identified in section 2.2.2: Rapid bus: An emergent transit product.

\subsection{2: Branding and marketing}

Discussion about the brand identity tended to focus on the livery of the vehicles themselves. Several interview participants pointed out that the key reason to reinforce the brand identity on the vehicles was that they act as a moving advertisement that a new type of transit service is on the street. It is a sign that something is new, and can encourage curious people to try out the service. Infrequent transit riders are also exposed to a new type bus and, as noted in section 2 , anecdotal evidence points to the ability of an impactful identity to capture attention. One participant received a substantial number of comments from members of the public (riders and non-riders) about the physical characteristics of the BRT system (vehicle design, station design, etc.). Another participant noted the inherent challenges for agencies, although he also agreed that the brand image was important. For example, a unique livery creates a sub-fleet for the rapid bus routes, and can add to operational and capital costs if only rapid buses can run on rapid routes.

\subsection{3: User experience}

In the opinion of one interview participant, the conventional planning process tends to be too fixated on the inputs of transit services (type of running way, fare collection, vehicle propulsion, etc.). Rather, the goal of the planning process is to be focused on the outputs (improving travel times, improving access to jobs, improving comfort, etc.). The end point is finding out what needs to be done to reach those goals (this informs the implementation plan). Possible directions in terms of mode and technology are revealed after physical constraints (e.g., limited street width) and available capital funding (e.g., cannot afford tunnelling) are considered. The participant continued to say that transit riders tend not to care about the transit technology as much as they care about the travel time, comfort, and convenience of the service.

Another participant pointed to the requirement of service planners at his agency to periodically ride services in order to see, first hand, how they are working. It tends to allow the planners to encounter operational issues as riders and transit operators and to attempt to address the situation. 


\subsection{4: Engaging the public}

One interview participant outlined a process whereby an active public was key to identifying areas of concern and for getting more stakeholders "on side." The starting point was to approach the community along a pre-identified corridor, and begin the discussion by admitting the bus service is slow. Additional data and information on route performance was presented to the public to start the conversation about how the service could be improved. The participant noted that if you start the conversation from an "inputs" perspective ("We need a bus lane here.") you open up the process to potential points of conflict between planner and public, and between different interest groups among the public. Rather, the opportunity is in asking questions like "Were do you need to go? Where are the problem areas? How do you think we can improve convenience and comfort?"

The participant continued, saying that the next step is to identify groups who would have an interest in bus transit improvements and invite these groups to participate in in-depth advisory committees. This may include nearby hospitals, schools, community centres, advocacy groups, and business associations. These advisory committee roundtables meet regularly and review and comment on every step of the planning and design process. It is a more involved process than a "town hall" type of open house, and a chance for members to hear the viewpoints of others whose interests might be in conflict with their own. The advisory committee is also an opportunity to educate the public on the merits and trade offs of public transit service design and a chance to identify what types of improvements are the most important to them. Occasionally, nongovernmental research institutes are able to assist the community advisory members in studying the mobility challenges in their area, and "adding structure to their argument." Ongoing and direct dialogue with the transportation operations and planning divisions, with the transit operating agency, and with various community actors including business representatives and social wellness groups as critical in the success of that particular project. At the very least, the dialogue is instrumental in softening the stance of opponent interest groups.

In general, noted the informant "the more we communicate, the better things go." Potential issues were identified (some were not known to planners) and captured in order to address in later consultation and design phases. Also, various parties who traditionally have divergent interests heard from others around the table. For example, business organizations that advocated for street space for delivery trucks and customer parking heard the perspectives of transit riders who are delayed in traffic due to the absence of a bus lane. 
Another participant spoke of different approaches to engagement. That agency uses yearly public information open houses to present upcoming service changes, and allow the public to interact with transit officials, should they have any comments or concerns. It is at these open houses that planners present the new on-street BRT services, which are planned for the near future. This participant noted that opinions among the public span a wide spectrum, and that "you can't expect to win everyone over."

\subsection{5: Champions}

One emerging aspect of successful implementation of bus transit project is somewhat subject to chance: the presence of the right combination of people at the right time in the right places.

One participant noted that the bus transit project he was involved in began first with changes in the workforce in both the planning agency and transit operator. Subsequently, free-form interdepartmental conversations began to occur regarding improvements to service and infrastructure. Next, a change in key leadership within both organizations saw the new leaders looking for projects to kick-start as part of their term.

Another participant noted that emergent stories in the media about climate change and traffic congestion informed public discourse and concern about urban sustainability. This helped foreground transit issues at City Council, and was instrumental in funding the implementation of several on street BRT lines.

\subsection{6: Small starts}

An interview participant who was involved in planning a series of rapid bus lines placed the approach to planning in a nutshell: the idea was to select a corridor, get something on the ground, and point to success for future planned corridors. Basically, it was a "proof-of-concept" approach, in a direction similar to that reviewed in 2.3.3: The silo mentality and unsustainable modes of thinking. The informant continued, saying the proof-of-concept approach afforded an opportunity to start small, learn from errors, and demonstrate a new form of success. The end product is local experience with improved bus services as a viable rapid transit solution, and to generate a library of local best practice with regard to rapid bus implementation.

Another participant faced considerable challenges in working interdepartmentally. The transportation operations division did not share the same priorities as the transit agency. He pointed out that there are other ways, beyond physical changes (e.g., "moving curbs") that service planners can improve service. For example, shifting service hours and implementing limited stop 
or express routes can allow for incremental improvement while avoiding a rigorous approval process.

\section{2: Rethinking the mechanics of bus transit}

\subsection{1: Network design}

Network design was a source of disagreement between interview participants. This may be due to the context specific nature of route network design: in a city with a regular grid pattern it may be easier to implement, but in a city with a curvilinear or irregular street pattern implementation is a significant challenge. One participant highlighted the importance of the network grid to his agency's service. He stressed that it provided connections and multiple route options for riders to select from. Further, he noted that significant off-peak ridership gains could be attributed to the convenience of the grid network. Other participant comments dealt with major constraints to implementing grid networks related to geographic features such as valleys, which disrupt the consistency of the grid, and the tension between suburban neighbourhood design and the disposition of arterial grid roads in relation to where residences are located in a neighbourhood. Another informant pointed out that the grid works well if density is dispersed around the perimeter or a neighbourhood, but some cities feature a community design which moves populations toward the centre, resulting in the need for most people to walk do and from the exterior of the neighbourhood. He also raised safety concerns about people waiting for buses along high-speed arterial roadways.

\subsection{2: Fare collection}

Participant feedback on reducing dwell times by addressing fare policies and procedures was mixed. One participant noted that off-board fare collection, while a costly investment, reduced dwell time by as much as a third, depending on the specific corridor. Anecdotally, it also reduced the frustration experienced by riders if a large group is boarding signal file through one door only.

There are a number of constraints, however, to implementing a proof-of-payment, self-service system. The capital cost is the first barrier, but this also affects operating costs. As another participant pointed out, the machines could be subject to vandalism and would require routine maintenance. Further, staff would have to drive around to all stops to collect the money from the machines. The same participant suggested self-service machines on board the vehicles as a lowercost alternative, and noted that the key question was if the additional costs are worth it, in terms of running time saved. 


\subsection{3: Constraints and limitations}

The bus has its limitations, even in a rapid bus format. Like any transit technology (or tool in a toolkit) there are specific circumstances where it is most applicable. While the theoretical capacity limit is around 3000 to 6000 ppdph (passengers per direction per hour), one participant noted that the limit is, from a practical perspective, around $2000 \mathrm{ppdph}$. This is because it is near impossible to schedule buses every 30 seconds. Two to three minutes is usually the minimum headway in mixed traffic operation. This can be contrasted with light rail rapid transit, which can carry up to around 20,000 ppdph with multiple vehicle consists. The same participant pointed to additional implementation challenges such as the availability of garage and maintenance space, the availability of bus bays at terminal locations, and the availability of additional operators to drive the new services.

Two participants echoed the point that space on a congested urban street is at a premium. There are competing demands for space (automobiles, bikeways, delivery, parking, pedestrian realm, etc.). One participant indicated that there is often insufficient space available to construct a busway so intermittent bus lanes were the only feasible alternative. The other participant pointed out that light rail guideways can be narrower than busways, lowering the width needed for a dedicated transit space.

Finally, success appears to occasionally present its own challenges. One participant pointed to the problem of overcrowding. If the ridership of a new service is under-forecasted, it is difficult to handle the demand by scaling up bus service. In his case, moving up the timeline for an articulated bus order assisted in handling the unanticipated passenger loads.

\subsection{4: Performance data}

One interview participant emphasized the importance of good, timely data for service planning. It takes resources and planning to develop a process to measure ridership and route performance. This can be done with automatic passenger counters or manual counts, but the data must be captured in a usable way, and transmitted promptly. The participant noted that his agency did not have a robust process to capture detailed and timely information. Without good data, it is difficult for service planners to know what is happening in day-to-day operations, make decisions about service changes, and make improvements to bus services. 


\section{3: Summary}

The perennial constraint, according to most of the participants, is money. Resources constrain what can be done to address sustainability and mobility issues in city. But since the determination of resources often occurs outside the jurisdiction of a transit operator or planning authority, participants were asked to speak to factors beyond funding constraints.

Feedback from participants thus fell along a spectrum from how transit professionals work to the "nuts and bolts" technical aspects of designing services. In general, the participants agreed that branding and communications is a good idea, with the physical components such as vehicle livery and brand expression playing a key role. Most participants faced challenges in working across departments and disciplines due to misaligned priorities. Working with other agencies can still be possible and valuable. In the case of one participant, a change in senior leadership at both the planning and operations agencies afforded an opportunity to invest in addressing mobility and performance issues on several bus corridors. In a similar vein, the interviews also revealed the importance of a project champion.

Active public engagement appeared to play a major role in at least one high-profile project. It assisted planning staff in discerning challenges faced by transit riders, and moderated the discussion by keeping everyone informed and all parties heard.

The key, echoed by at least two informants, is that each component of the service informs the whole user experience, and planners should focus on how these components address mobility challenges faced by transit riders (the outputs). Insights on components such as a grid route network for bus services and off-board fare collection were mixed. One informant who had extensive experience with a grid network emphasized its importance in the effectiveness in providing service. Another participant had concerns with how a grid could be implemented in his municipality, due to the local details of neighbourhood and street design. 


\section{5: Recommendations}

The following section contains ten recommendations formulated from the literature review and feedback from the informant interviews. The literature review set out the scope of the problem, which consists of barriers to addressing urban sustainable mobility challenges, the contemporary role of the bus as a primary vehicle technology of urban transit, negative perceptions of bus transit, and the fundamental components of bus transit system design. The role of the interviews was to test these findings based on the insights of the participants to determine whether or not they are achievable in practice.

The ten recommendations below reflect the need to change planning approaches (getting it done in practice) and the need to change the way bus transit functions for the transit user (rethinking the mechanics), and each is linked by symbol to a different type of planner:

- Transportation Planners [TP] are responsible for needs assessments, big picture network planning, and facilitating public engagement on such endeavours as a transportation master plan or official plan. They may work in transportation services departments, regional transportation agencies (such as Metrolinx) or in city planning departments (such as the City of Toronto).

- Infrastructure Planners [IP] are those assigned to the planning process of a particular capital project, such as a new rapid transit line. The end product of such work is typically an environmental assessment. They may work for a transportation services department, a specific project office (such as the Eglinton Crosstown), or a regional agency (Metrolinx)

- Service Planners [SP] are typically situated within a transit agency and are responsible for the day-to-day operational planning of transit systems as well as making adjustments based on shifts in demand.

- Others [OTH]. This group includes professionals in a number of roles including senior leadership positions at the City of Toronto and the TTC, or communications and marketing staff at the TTC. 


\section{1: Getting it done in practice}

Since urban mobility issues, like sustainability issues, are enormous, multivariate, and complex, there is a parallel between addressing sustainability issues writ large and implementing a smallscale transit project. Dale (2001) notes that bureaucratic and professional "siloing" is one such barrier and proposes that integrated decision-making is a more useful method at discovering the characteristics and deep truths of sustainability challenges, and developing possible courses of action to address them, than the contemporary rigid hierarchies of bureaucracy and professions. She proposes ways to break through the silo mentality.

Dale notes that " $[r]$ ather than tight hierarchal structures, we need fora that are diverse and that can support the coupling of ideas for emergent innovation and creativity, especially locally" (Dale, 2001, 116). She looks to several approaches from others, and advances the concepts of strategic questioning and a principled, pluralistic, and multi-perspective discussion (fora). The objective is to reach what Dale refers to as collaborative efforts across disciplines and an informed, holistic process for decision makers (Dale, 2001, 153). Strategic questioning allows us to integrate other ways of knowing in addition to discreet instrumental rationality. Managing change is a participatory and interdisciplinary process, where we must learn from our success and from our mistakes. Further, rather than focusing on megaprojects, we should focus on incremental, meaningful gestures, where we can demonstrate and acknowledge our successes, but also learn from our failures (Dale, 2001, 113).

Second is the bringing together multiple voices from the widest array of experiences possible in a dialogue. The objective is to identify and make explicit the trade-offs in various policy directions, encourage creative and flexible responses to constraints, identify current gaps in information and knowledge, break the gridlock-inducing hierarchy, and respond to the horizontal nature of contemporary challenges (Dale, 2001, 112-114). Pluralistic conversation and interdisciplinary collaboration combined are visualized in Figure 17. The entire model exists within the problem of urban sustainable mobility and multiple silos of traditional bureaucratic processes. At the bottom is the first stage, interdisciplinary and multi-stakeholder conversations, formal or informal. At the second level is continued horizontal interdisciplinary or interagency collaborative effort. The objective is to reach the top strata, the emerging policy and services aimed at addressing sustainable mobility. 


\section{Figure 17: Visualization of pluralistic fora and collaborative model (Dale, 2001, pp. 115 and 153)}

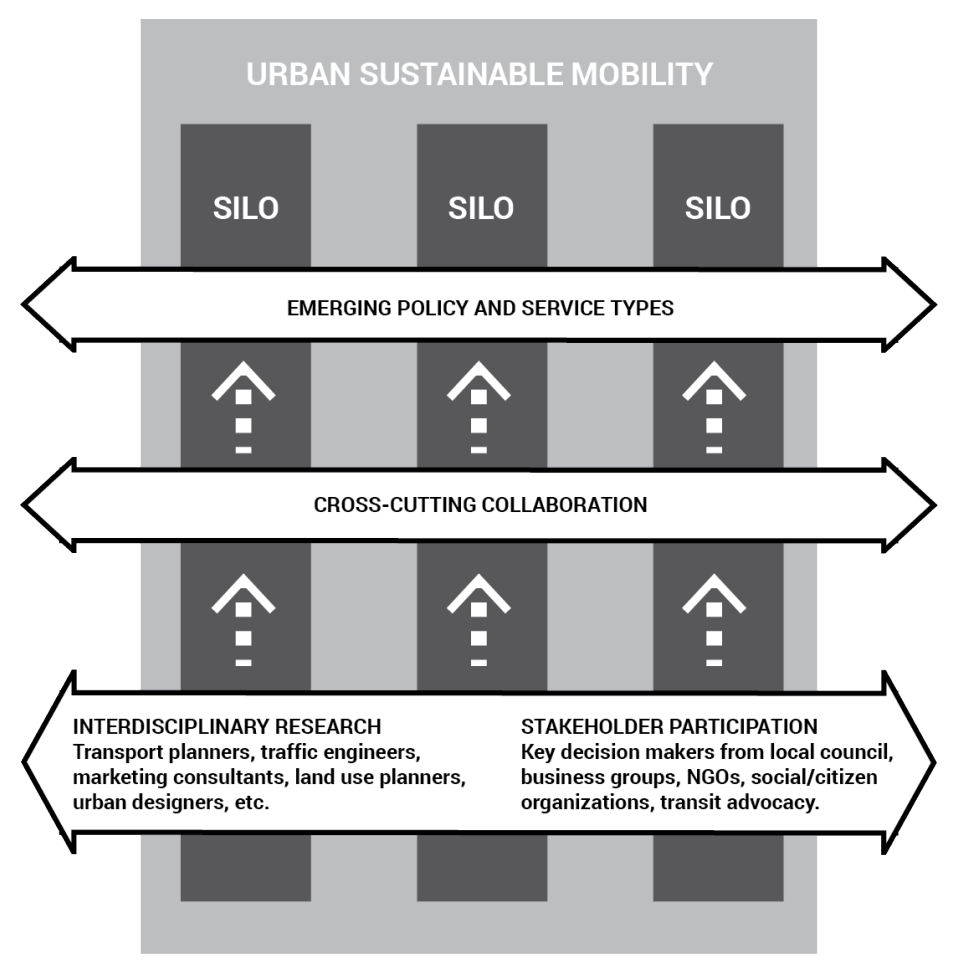

There are two ways that collaborative methods and pluralistic fora could assist planners working with bus service challenges. The first is in creating advisory groups such as those used by one of the participants above. They would allow transit riders, business leaders, and other stakeholders to not only voice concerns about trouble spots in existing services and the proposed plan, but collectively attempt to identify shared interests and gaps in knowledge. The planner would them capture this information and refine the plan.

Planners should remain aware of changes in senior leadership at their agency or related agencies. New leaders may be looking for interesting projects to kick-start, such as a rough plan for improving bus transit on certain corridors.

Pessaro, et al., (2012) note that a "lesson learned" by the planners of the EMX BRT system in Eugene, Oregon, was to shop the project around City Hall and secure a political sponsor, such as a city councillor. This "project champion" is someone who could ensure momentum for funding, broker relations with stakeholders and city council, and help spread information to the public and 
other officials about the idea for the rapid bus system. Champions appear to be a useful resource in securing authority, support, and "buy-in" for a project.

According to one interview participant, conversations with staff from other disciplines regarding interesting ideas and emerging approaches to solving local mobility challenges brought about the idea of a rapid bus type of system.

In summary, planners should maintain open communication with other departments and agencies, and keep themselves up to date with other professions. The goal is to have open dialogue and identify links and compromises were none were visible previously. As one interview participant put it, "It is not rocket science. It takes resources, organizational momentum, and collaboration."

Recommendation 1 [TP]: The region as a whole has a vision for transit (The Big Move and the various official plans) but clarification should be sought on the role of transit. Questions that could guide public discussion include: What is the value of public transit to the residents of a city/users of that transit system? What would happen if it were switched off? To what extent is public transit supposed to be equitable (service spread out evenly), or geared towards promoting ridership (service focused on areas with high ridership growth potential)? The results would form the basis for future regional transportation plans along with the policies that determine how and where transit operating budgets are allocated.

Recommendation 2 [AD/IP/SP]: A TTC bus network improvements project office ("project office") should be created. It should take a holistic approach in identifying and implementing improvements. It should be shared jointly by the TTC and the City of Toronto, Transportation Planning division. It should be geared to implement changes in high-need corridors in the short term (one to ten years), and its infrastructure and service planners should maintain close coordination with Metrolinx and the TTC marketing and communications unit.

Recommendation 3 [IP/SP]: Staff at the project office should emphasize working horizontally. This means that planners should present their ideas and progress to appropriate parties in other disciplines and agencies. For example, information exchanges between the project office and the Transportation Services Dept., City Planning Dept. (land use planners), Toronto Public Health, etc. The idea is to keep dialogue open, ideas aloft, issues on the table, and plans circulating. Further, project office staff should seek project champions in senior leadership and city council, and present progress. 


\section{2: Meaningful public engagement}

Attempting to minimize the number of people who are taken by surprise by a particular transit project is as important as learning the on-the-ground stories and struggles of transit riders' experience with the system. But a planner could go further by actively engaging the public and helping them become actively involved in planning that particular piece of transit infrastructure. As one participant stated with regard to public engagement: "Generally, the more we communicate [with the public], the better things tend to go."

It appears that there is considerable variation in the way the public has been involved in planning bus transit systems. Based on the materials available on project websites as well as the interviews, some of the agencies reviewed went through a lengthy public involvement process, while the process was more limited in other jurisdictions.

For example, the New York Dept. of Transportation used a "BRT game" during the consultation phase for the Select Bus Service project. Participants used the game board to discuss and vote (in a fashion similar to dotmocracy) for the element that they thought would improve service the most.

Figure 18: BRT features "dotmocracy" game (NYDOT/MTA, 2009b)

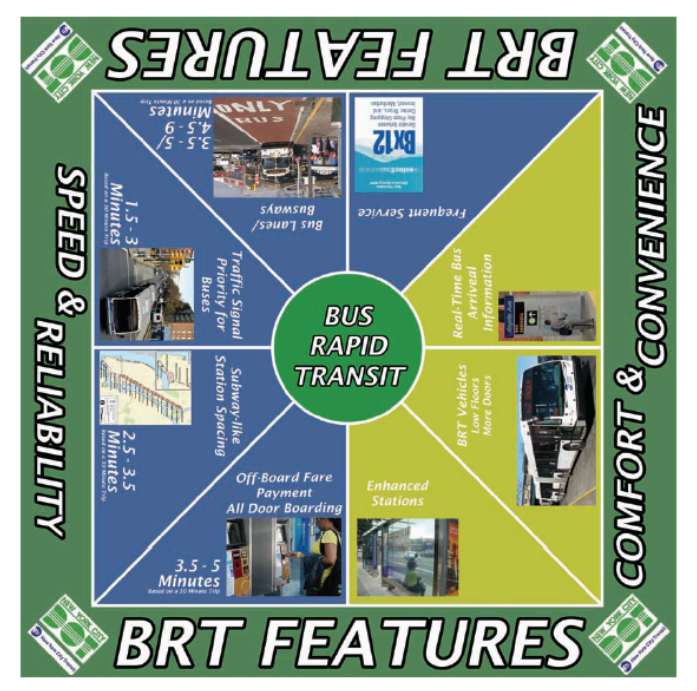

Recommendation 4 [IP/SP]: In addition to working horizontally, planners in the project office should work vertically by taking a "roll up the sleeves" approach and actively engaging the public as part of the preliminary planning phase. The problems with existing service should be set out clearly to the public. The public's feedback should be encouraged and captured. Creative tools such as custom dotmocracy games, large-scale maps, and online cross section tools (such as 
Streetmix, www.streetmix.net) can help visualize the trade-offs involved in designing transit improvements.

Recommendation 5 [IP/SP]: Planners working in the project office should consider multistakeholder advisory groups for the planning, detailed design, and construction phases of bus improvement projects. Leaders from stakeholder groups should be identified and invited to an advisory committee that meets periodically through the duration of a project. The physical format could include roundtable discussions of 8 to 10 people, with a total of 30 to 50 involved, depending on local circumstances.

\section{3: Small starts}

The low-cost and fast implementation nature of on street BRT or rapid bus, is conducive to thinking about it as a proof-of-concept, "small start" type of project. It would be less feasible to take such an approach with rail, given the increased infrastructure requirements such as track, signalling, overhead wires for electric vehicles, and maintenance and storage facilities.

Depending on local circumstances, even a small start may be too large. A participant from another municipality noted that in the face of too many obstacles caused by an interdepartmental silo mentality, modal bias, and conflicting departmental priorities, physical changes (busways, bus lanes, queue jumps, stop changes, fleet purchases, etc.) can be set aside. Instead, a service planner can attempt to change routes, schedules, and stopping patterns in a way that emulates onstreet BRT without the physical elements. These changes may not require the extensive oversight and approvals compared to "moving curbs" (such as a capital funding agreement or an environmental assessment).

Recommendation 5 [IP/SP]: Transit planning authorities (department of transportation or the transit agency) should start with a distinct pilot or "proof-of-concept" project, point to the successes, and learn from what did not work well.

\section{4: Branding and marketing the bus}

Car manufacturers market an object (the car) using lifestyle images and emotional response. As Cain, et al. (2009) note, the traditional method of tackling branding and marketing for public transit agencies is to sell a service (transit) but use only the facts about the service as the selling points. For example, "There is a new Route 23, and it runs between place A and place B every 15 minutes." This fact-based marketing may have utility, but only to the existing ridership. If transit 
agencies want to attract new (discretionary) riders in order to promote transit uptake and travel behaviour change, the emerging trend is to sell the service with lifestyle images and emotional response rather than mere facts. Transit can be embedded creatively into the living tissue of the city by association with major sports or cultural events and also with emerging restaurants and entertainment districts. Sakaria and Stehfest (2013) note that the latter appeals to the millennial generation, who are more amenable to using transit as a first choice then previous generations.

The image of transit in generally considered critical in terms of the perception the public has of the brand as well as how it is expressed at the various points of contact with the transit system (at the stops/stations, website, the vehicle, etc.). Not addressing the brand image has allowed the car to surpass transit as being both a rational transit choice and a lifestyle option with emotional attachments. Consideration of brand identity and expression is generally accepted as best practice in promoting bus transit, which lacks the innate attractiveness of rail and relies on additional brand elements to set out its distinct service offering. Addressing the brand image has been shown to have modest positive effects on the perception of transit and the potential for discretionary riders to use transit more often. In considering brand image as part of a new service product such as a rapid bus system, planners do not need to be graphic designers or marketing experts themselves. They just need to, in the words of one participant, "speak the lingo."

Recommendation 6 [OTH/IP/SP]: Staff at the project office should embrace the basics of branding and communications. Consideration should be given to thinking of future rapid bus services in a holistic way, with the user experience and brand being key factors in addition to the functional attributes. Close coordination with a brand image consultant and TTC communications and marketing staff is critical. Several approaches identified in the literature review can be used, such as:

- Brand is part of institutional structure. A high-level senior leadership position at the TTC should be responsible for brand management, marketing, and communications.

- Differentiate from the competition and do not blend-in. Foreground physical aspects of transit (vehicles, stop design, marketing materials) using consistent and impactful design.

- Avoid the word "bus" and its negative connotation. The brand name can used to distinguish rapid vehicles from traditional buses: MAX, Metro Liner, RapidRide, etc. An appropriate name already used in Toronto is "Rocket," but the public can be engaged to generate a visible and meaningful brand. 


\section{5: The mechanics}

The first objective is to address sustainability challenges by reducing travel times so that transit is more competitive with the car. The intent is to increase transit modal share by attracting discretionary riders. The second is to spread the rapid transit network out further from existing rail rapid transit lines in order to address the spatial mismatch of transit and ideal transit markets. For discretionary riders, perceived service frequency and reliability are the most important factors, and these must be addressed through infrastructure design (dedicated guideway, bus lanes, transit priority signal, etc.) and resources (operating funds).

The key considerations include grid route networks, which are becoming increasingly common among transit providers for several reasons:

- Efficient use of limited operating funding

- Any point to any point connectivity

- Higher frequencies with the same resources

- Straighter running - fewer deviations and turning delays (Nielsen, et al., 2005; Mees, 2010; Walker, 2012)

Another consideration is the collection and monitoring of fares, which must be done through the front door with inspection by the operator. This is a major source of delay for transit buses. Implementing off-board collection through the deployment of fare machines at stops should be given consideration. Proof-of-payment policies and fare inspectors can be used to enforce fare policy. Experience in New York on implementing the Select Bus Service's proof-of-payment policy indicates that fare evasion decreased (NYDOT/MTA, 2009b). The practical advantage to off-board collection is that riders can board and alight at all doors, which in the case of articulated buses is a distinct benefit.

Finally, best practice literature reports that if stops are too frequent average travel speeds can slow substantially. Several interview participants noted that common practice in North America is to place stops at short intervals (of around 200 to 250 metres, or even less in some cities). As part of the "Getting it done" process outlined above stops should be relocated or removed so that they are not less than 400 to 500 metres apart. As an alternative, a limited or express overlay line can be implemented which skips many of the lesser-used stops in favour of major trip generators, major cross streets, and connection points. 
Recommendation 7 [TP/IP]: Planners working in big picture regional planning, or in addressing mobility concerns along a high-need corridor, should avoid beginning the process with a vehicle technology in mind. The final technology should emerge from the planning process, and the constraints and opportunities that limit what can be done. In other words, the focus should be on outputs (goals and objectives such as a more liveable city, decreased travel times, access to more jobs, etc.) rather than the inputs (we need a LRT or BRT line).

Recommendation 9 [TP/IP]: The project office should work to improve the travel speed, reliability, and user experience for the identified high-need bus corridors. Consideration should be given to express overlay service, stop consolidation and minimum distances ( $>$ than $400 \mathrm{~m}$, for example), all-door boarding/off-board fare collection, upgraded shelters, queue jumps, level boarding platforms, etc.

Recommendation 10 [OTH/SP]: The project office should work with operational departments (such as TTC Fleet Services) to ensure that quality data on ridership and route performance can be captured to the extent necessary to develop profiles of each high-need corridor. Good data is particularly important for revealing the "story" behind each route Recommendation 4. 


\section{6: Conclusion}

In terms of addressing the three-pronged sustainability challenges faced by cities, bus transit is the wildcard we never knew we had in our hand. Many transit agencies run bus services on highridership corridors that are slow and inefficient. By not addressing the stigmatized image of bus transit, we are missing opportunity to use an effective tool in meeting the long-term sustainable mobility needs of cities.

The interviews with planners and transit staff revealed that although it is not a direct task of planners per se, branding and marketing bus transit is typically considered important. Further, ways of working across disciplines (such as maintaining cross-departmental dialogue and finding project champions) and with the public (such as multi-stakeholder advisory groups and charettesstyle meetings) assisted with moving projects to implementation. Mixed results emerged from the discussion regarding the technical aspects (network design, fare collection, stop spacing, etc.). This is probably due to the varying constraints that differ from city to city and agency to agency. The lack of financial resources are always a concern, as is the positioning of the right people at the right time, but some bus transit projects do advance. There is a saying that creativity thrives in restraint, and it certainly seems applicable to the implementation these systems.

\section{1: Limitations}

This study is the author's attempt to structure findings and thoughts regarding the perception of bus transit, interdisciplinary considerations for planners, and addressing urban sustainability issues. Is the bus overlooked? Derided? Undervalued? It is an inherently qualitative question, and examines the role of the planner and the transit rider. Secondary findings regarding performance, financial, and statistical data were reviewed.

The objective of the interviews was to describe the story of professional planners' involvement in transit planning, particularly with regard to bus transit, and to build a set of best practice guidelines that could identify knowledge gaps and contribute to the dialogue in this area. As the sample was not likely representative, response bias is probable. Primary quantitative analysis was not considered appropriate for the scope of this project. 


\section{2: Reflection}

Transit service planners work in a multiagency context and interact with other professions. This appears to be particularly evident with planning rapid bus transit systems, such as rapid bus, and may be due to the involvement of an array of operational departments, administrative departments, agencies, and disciplines. Further, planners working in North America's metropolitan centres are exposed to sustainability pressures, such as reducing emissions, encouraging travel behaviour change, spatial mismatch of transit service, and the economic effects of traffic congestion. Given this, what are the implications for a planner's work in this context? Should planners take an advocacy role, and push a concept or idea forward rather than waiting for direction from city council? This appears to be a driving factor in the experience of at least two of the interview participants.

In terms of defining the planner's role in rethinking bus transit, it may be helpful to review the code of practice of the Canadian Institute of Planners. The code states that a planners' primary obligation is to define and serve the public interest, which not only includes the health and safety of the public, but their values, needs, and aspirations (CIP, 2014). Planners are also required to leverage communication techniques to inform and structure debate and assist the public in understanding opaque planning and urban systems concepts. While the emphasis on the communicative nature of planning and the duty to the public interest implies an advocacy role it clearly sets out an obligation to active engagement, both with the public and with other professions. The interviews revealed that multi-stakeholder advisory groups, design charettes, and frank interdisciplinary conversations hold promise in addressing urban sustainability challenges. It is not only important for a planner to be "active," it is arguably a professional requirement. It also serves to assist planners working to address sustainable mobility challenges.

\section{3: Directions for future research}

One of the challenging aspects of this study was that the question of how to improve the image bus transit is broad and complex. It spans the details of service provision, marketing and communications, and high-level subjects such as organizational administration. It was impossible to cover everything here. Several salient questions emerged from the literature review and the interviews that could serve to direct future research. 


\subsection{1: The application of grid networks}

Focusing transit service on a grid of high-frequency, direct routes decreases network complexity and increases productivity and the attractiveness of transit service for discretionary riders (Currie and Wallis, 2008; Brown and Thompson, 2011; Walker, 2012). Feedback from several interview participants corroborates this. However, one participant pointed out that he had significant concerns regarding the idea of people waiting for transit at stops along high-speed arterial roadways. Waiting in such as space, even if a shelter is provided, could be uncomfortable and unattractive due to motor vehicle traffic noise, speed, and volume.

The applicability of a high frequency network appears to also be contingent on local context, with factors such as climate and neighbourhood design contributing to the usefulness of grid route networks. For example, grid networks often require riders to walk further in order to reach a higher frequency service. Yet some Canadian municipalities experience daily winter temperatures of -30 degrees Celsius along with ice build-up on sidewalks, turning a good walking environment in the summer into an impassable one in the winter. This is further compounded by frequent gaps in sidewalks or streets that have no sidewalks at all. Further, some suburban neighbourhood designs concentrate higher density residential zone or activity generators at the centre, rather than the periphery where the arterials roadways are located. As result, transit cannot access the higherdensity portions of the neighbourhood.

Grid networks appear to be a compelling concept, however further study is needed to see if they are a good idea in in the context of a Canadian winter city.

\subsection{2: Ridership response to brand revitalization}

Rebranding often accompanies significant transit improvements, such as a new bus rapid transit line. In fact, best practice for BRT implementation underlines the importance of branding the service. It is unclear what portion of the ridership increase, which often accompanies a new service, is due to the tangible attributes of the service (speed, reliability, etc.), or the intangible attributes (improved image, stylishness, comfort, etc.).

In other words, there does not seem to be quantifiable evidence that transit riders are seeking an up-to-date and stylish image for transit in considering their travel options. Rider preferences in terms of assessing attributes appear to be in line with their hierarchy of needs. In other words, attributes such as personal safety, service reliability, and competitive travel times need to be satisfied first, before riders and potential riders are interested in stylish transit vehicles and station 
designs. It is difficult to argue that transit agencies should invest in a good quality brand image beyond anecdotal evidence and generally accepted industry best practice.

Additional evidence in this area would assist agencies that have limited experience with revitalizing a brand identity to argue the case for the resources to do so. Alternatively, this may underscore the need to address tangible factors along with the intangible, in what Cain, et al. (2009) refer to as a "holistic package."

\section{4: The end of the line}

Researching this study has yielded some surprising findings for the author. For example, perhaps the relationship between transit and environment should not be taken for granted. According to the IPCC, the relationship between public transit and reduced GHG emissions is tenuous at best. Ridership on public transit in North America (particularly in the United States) must increase substantially in order to offset the increased emissions from large transit vehicles. Investing in public transit improvements in order to boost ridership seems like a good idea, if not for ecological reasons, but for the economic and social equity reasons. It can reduce congestion and provide access to jobs and leisure activities for those with low incomes or no access to a car. As spatial mismatch can jeopardize access to opportunity such as employment and cultural engagement, perhaps there should be a right to mobility. If there isn't, should there be?

Moving forward into this election year, we can hopefully have an intelligent discussion about how to get Torontonians moving sooner rather than later. Hopefully, all options would be considered, not just the capital-intensive modes. It is the author's conclusion that the rethought TTC bus holds tremendous promise. 


\section{7: References}

Adler, P., V. Bednar, Z. Matheson. (2010). The Geography of Toronto's Service Class and What It Means for the City Of Toronto. 2010 Toronto Election Discussion Paper. Retrieved from: http://www.martinprosperity.org/media/pdfs/Toronto election seriesGeography of Service Class.pdf

Aguirre-Livingston, P. (June 10, 2013). An ode to the vomit comet. Blog post on The Grid Toronto. Viewed on March 31, 2014 at: http://www.thegridto.com/life/society/the-night-shift-an-ode-to-thevomit-comet/

Amin, A., B. Arimah, K.J. Barrett, M. Halfani; I. Jensen; M.K. Kinyanjui; U. Mbeche; E.L. Moreno; R.O. Otieno; E. Abera Yemeru. (2013). Planning and Design for Sustainable Urban Mobility: Global Progress Report on Human Settlements 2013. New York: Routledge.

APTA [American Public Transit Association]. (2013). 2013 Public Transportation Fact Book, Appendix A: Historical Tables. National Transit Database. Retrieved on November 10, 2013 from: http://www.apta.com/resources/statistics/Pages/transitstats.aspx

Arpi, E. (December 8, 2009). Transit agencies need to invest in marketing: A lesson from Los Angeles. Blog post on The City Fix/EMBARQ. Retrieved from: http://thecityfix.com/blog/transit-agenciesneed-to-invest-in-marketing-a-lesson-from-los-angeles/

Bertaud, A., B. Lefèvre, and B. Yuen. (2011) "GHG emissions, urban mobility, and morphology: A hypothesis." Chapter 4 of Cities and Climate Change: Responding to an Urgent Agenda. [Hoornweg, D., M. Freire, M.J. Lee, P. Bhada-Tata, and B. Yuen, eds.]. Washington, DC: The World Bank.

Brampton, City of. (2005). Brampton Rapid Transit Initiative: Submission to the Transportation Association of Canada Sustainable Urban Transportation Award. Report by the City of Brampton.

Brown, J., \& Thompson, G. (2011). Hubs, Spokes, The Grid, and The Future of Transit: The Importance of System Planning for Public Transit's Success. Retrieved February 21, 2014, from Transportation Research Board: http://www.trb.org/annualmeeting2011/annualmeeting2011.aspx

Bruun, E. C. (2014). Better Public Transit Systems: Analyzing Investments and Performance. New York, NY: Routledge.

Cain, A., J. Flynn, T. Reyes, and M. McCourt. (2009). Quantifying the Importance of Image and Perception to Bus Rapid Transit. Washington, DC: US Dept. of Transportation/Federal Transit Administration.

Calderone, E. (2010). LA Metro: Promoting Mass Transit. Video for EMBARQ. Viewed on March 20, 2014 at: http://vimeo.com/7984623

Calgary Transit. (2013). Calgary Transit Map. Retrieved from www.calgarytransit.com.

CIP [Canadian Institute of Planners]. (2014). Code of Professional Conduct. Website viewed on April 10, 2014 at: http://www.cip-icu.ca/web/la/en/pa/c59dde35f1184b5e89385e53506c19f8/template.asp

Campbell, S. (1996) Green cities, growing cities, just cities? Urban planning and the contradictions of sustainable development. Journal of the American Planning Association, 62, 3.

Capital Metro. (2012). "MetroRapid to receive \$38 million federal grant." News release. Viewed on March 1, 2014 at https://www.capmetro.org/news-item.aspx?id=2799

Chicago Dept. of Transportation (2013). Complete Streets Chicago. Retrieved from: http://chicagocompletestreets.org/

Chow, O. (April 7, 2014). "Olivia Chow: To fix transit, we need a relief line — and more." Toronto Star. Viewed on April 7, 2014 at http://www.thestar.com/opinion/commentary/2014/04/07/olivia_chow_to_fix_transit_we_need_a_reli ef_line_and_more.html

Currie, G., and A. Delbosc. (2013). Exploring comparative ridership drivers of bus rapid transit and light rail transit routes. Journal of Public Transportation, 16(2), 47-65. 
Currie, G. and I. Wallis. (2008). Effective ways to grow urban bus markets - a synthesis of evidence. Journal of Transport Geography 16, 419-429

CUTA [Canadian Urban Transit Associtaion]. (2013). Vision 2040 Progress Report. Retrieved from: http://www.cutaactu.ca/en/public-transit/publicationsandresearch/vision_2040.asp

Dale, A. (2001). At the Edge: Sustainable Development in the 21st Century. Vancouver, BC: UBC Press.

Danaher, et al. (2004). Transit Capacity and Quality of Service Manual, $2^{\text {nd }}$ Edition. Report by the Transit Cooperative Research Board. Retrieved from: http://www.trb.org/Main/Blurbs/153590.aspx

Dunphy, R., R. Cervero, F. Dock, M. McAvey, D. Porter, and C. Swenson. (2004). Developing Around Transit: Strategies and Solutions That Work. Washington, DC: Urban Land Institute.

Edmonton, City of. (2009). The Way We Move: Transportation Master Plan. Retrieved from http://www.edmonton.ca/city_government/documents/land_sales/TransportationMasterPlan.pdf

Environment Canada (2013). Canada's Emissions Trends 2013 . Retrieved March 20, 2014, from http://www.ec.gc.ca/ges-ghg/

FCM [Federation of Canadian Municipalities]. (2007). National Transit Strategy. Policy document of the Big City Mayors' Caucus. Retrieved from: http://www.fcm.ca/Documents/reports/National_Transit_Strategy_EN.pdf

Field, C. B., et al. (2014). IPCC 2014: Summary for Policymakers. In: Climate Change 2014: Impacts, Adaptation, and Vulnerability. Contribution of Working Group II to the Fifth Assessment Report of the Intergovernmental Panel on Climate Change. Retrieved from: http://www.ipcc-wg2.gov/AR5/

Finn, B. (2010). Bus with higher level of service in European cities. Conference presentation at Defining Bus Rapid Transit Workshop, Transportation Research Board Annual Meeting 2013. Retrieved from: http://www.nbrti.org/TRB2013_BRT_Workshop.html

Forsey, D., K.N. Habib, E. Miller, and A. Shalaby. (2012). An evaluation of the impacts of introducing a new transit system on commuting mode choice and transit ridership: A case study of the VIVA BRTlite system in Toronto. Paper presented at the 2012 TRB Annual Meeting.

Gomez-Palacio, A. (2014). "The opportunity of transit urbanism.” Municipal World, March 2014, 17-21.

Grescoe, T. (2012). Straphanger: Saving our Cities and Ourselves from the Automobile. New York, NY: Times Books/Henry Holt.

Grewal, S. (June 2, 2006). A new life, living in transit: Thousands of recent immigrants spend much of their day on public transit, watching suburbs blur by from home to work. Toronto Star.

Harrison, M. (November 27, 2012). Photo of Rapid Ride vehicle. The Seattle Times. Retrieved from: http://seattletimes.com/ABPub/zoom/html/2019777005.html

HDR. (2008). Costs of Road Congestion in the Greater Toronto and Hamilton Area. Report prepared for Metrolinx. Retrieved from: http://www.metrolinx.com/en/regionalplanning/costsofcongestion/costs_congestion.aspx

Heffner, R., T. Turrentine, and K. Kurani. (2006). A Primer on Automobile Semiotics. Retrieved from: file://Users/mark/Downloads/2006-UCD-ITS-RR-06-01.pdf

Henry, L., and T. Litman. (2013). Evaluating New Start Transit Program Performance: Comparing Rail And Bus. Victoria, BC: Victoria Transportation Policy Institute.

Hemily, B. (2004). Trends affecting public transit's effectiveness: A Review and Proposed Actions. Report for American Public Transit Association.

Hemily, B., and R. King. (2008). Uses of Higher Capacity Buses in Transit Service: A Synthesis of Transit Practice. TCRP Synthesis 75. Washington, DC: Transportation Research Board.

Heinberg, R. (2010) The End of Growth: Adapting to Our New Economic Reality. Gabriola Island, BC: New Society.

Hess, P. and J. Farrow. (2011). Walkability in Toronto's High-Rise Neighbourhoods. Retrieved from City of Toronto Tower Renewal website: http://www.toronto.ca/tower_renewal/reports.htm

Howes, A. and T. Rye. (2005). HiTrans Best Practice Guide 2: Public Transport-Citizens Requirements. Rogaland County Council, Norway. Retrieved from: http://www.urbanizationist.com/?p=216

Hulchanski, J.D. (2007). The Three Cities Within Toronto: Income Polarization Among Toronto's Neighbourhoods, 1970-2000 (Research Bulletin 41). Retrieved from Centre for Urban and Community Studies website: 
http://www.urbancentre.utoronto.ca/pdfs/researchbulletins/CUCSRB41 Hulchanski_Three_Cities_To ronto.pdf

Hulchanski, J.D., L.S. Bourne, R. Egan, M. Fair, R. Maaranen, R.A. Murdie, and R.A. Walks (2010). The Three Cities Within Toronto: Income Polarization Among Toronto's Neighbourhoods, 1970-2005.

ITDP [International Transportation and Development Policy]. (2013). The BRT Standard 2013. Retrieved from: https://go.itdp.org/display/live/The+BRT+Standard+2013

Kahn Ribeiro, S., S. Kobayashi, M. Beuthe, J. Gasca, D. Greene, D. S. Lee, Y. Muromachi, P. J. Newton, S. Plotkin, D. Sperling, R. Wit, P. J. Zhou. (2007). Chapter 5: Transport and its infrastructure. In: Climate Change 2007: Mitigation. Contribution of Working Group III to the Fourth Assessment Report of the Intergovernmental Panel on Climate Change [B. Metz, O.R. Davidson, P.R. Bosch, R. Dave, L.A. Meyer (eds)]. Retrieved from: http://www.ipcc.ch/publications_and_data/ar4/wg3/en/contents.html

Kalinowski, T. (March 26, 2014). Councillor wants TTC to add express buses to cut crowding. Toronto Star. Viewed on March 26, 2014 at http://www.thestar.com/news/gta/2014/03/26/councillor wants ttc to add express buses to cut cro wding.html

Keenan, E. (March 12, 2014). "Steal this platform!” Blog post on The Grid Toronto. Viewed on March 12, 2014 at http://www.thegridto.com/city/politics/steal-this-platform/

Kitchen, H. (2002). Municipal revenue and expenditure issues in Canada: Canadian tax paper no. 107. Toronto: Canadian Tax Foundation.

Kunstler, J.H. (2006). The Long Emergency: Surviving the End of Oil, Climate Change, and Other Converging Catastrophes of the Twenty-First Century. New York: Grove Atlantic.

Lau, S. (2007). Towards Inclusive Public Transport: Immigrant Mothers and their Daily Mobility (Master's thesis). Retrieved from: www.geog.utoronto.ca/graduate/planning/student-work/cip/200607-Towards-Inclusive-Public-Transport-LAU.pdf

Layman, R. (2005). Flickr user. Scan: Creeps \& weirdos GM ad against transit. Retrieved from: www.flickr.com/photos/rllayman/9006896/

Lerch, D. (2007). Post Carbon Cities: Planning for Energy and Climate Uncertainty. Sebastopol, CA: Post Carbon Press.

Levinson, H., S. Zimmerman, J. Clinger, J. Gast, S. Rutherford, and E. Bruhn (2003). Bus Rapid Transit: Volume 2: Implementation Guidelines. TCRP Report 90. Washington, DC: Transportation Research Board.

Litman, T. (2013). Evaluating Public Transit Benefits and Costs: Best Practices Guidebook. Victoria, BC: Victoria Transportation Policy Institute.

MacDonnell, S., D. Embuldeniya and F. Ratanshi. (2004) Poverty by Postal Code: The Geography of Neighbourhood Poverty, City of Toronto, 1981 - 2001. Report for the United Way of Toronto.

Martin Prosperity Institute. (2011). Transit Deserts \& Hulchanski’s Three Cities. Retrieved from: http://martinprosperity.org/2011/01/06/transit-deserts-hulchanskis-three-cities/

Martin Prosperity Institute. (2012). The Many Cities of Toronto's Public Transit. Retrieved from: http://martinprosperity.org/2012/08/09/the-many-cities-of-torontos-public-transit/

McConnell, R. (2008a). LACMTA 7598 on 6th Street in downtown Los Angeles, on route 447. Under pseudonym "The Port of Authority." Retrieved from: http://en.wikipedia.org/wiki/File:Metro-Express577.jpg

McConnell, R. (2008b). A NABI 40-LFW CNG bus on LACMTA Metro Express route 577x. Under pseudonym "The Port of Authority." Retrieved from: http://en.wikipedia.org/wiki/File:Metro-Express577.jpg

McConnell, R. (2008c). A NABI 45C-LFW bus on LACMTA Metro Rapid Route 780, on Colorado Blvd. and Rockland Ave. in Eagle Rock, California. Under pseudonym "The Port of Authority." Retrieved from: http://en.wikipedia.org/wiki/File:Metro-Express-577.jpg

Mees, P. (2010). Transport for Suburbia. Sterling, VA: Earthscan. 
Metrolinx. (2008). The Big Move: Transportation in the Greater Toronto and Hamilton Area. Regional Transportation Plan. Retrieved from: http://www.metrolinx.com/thebigmove/Docs/big_move/TheBigMove_020109.pdf

Metro Transit. (2014). The A Line: Snelling Bus Rapid Transit (BRT). Website viewed on April 2, 2014 at: http://www.metrotransit.org/snelling-brt

Munro, S. (2012, May 28). Analysis of 36 Finch West for November 2011 \& March 2012 (Part I) (Updated). Retrieved March 9, 2014, from: http://stevemunro.ca/?p=6291

Murphy, D. (2013). Pinterest user. Photo of DeVry University advertisement on bus stop shelter. Retrieved from: www.pinterest.com/pin/197876977349490357/

Neilsen, G. et al. (2005). HiTrans Best Practice Guide 2: Public Transport-Planning the Networks. Rogaland County Council, Norway. Retrieved from: http://www.urbanizationist.com/?p=216

Neuman, W.L. (2011). Social Research Methods: Qualitative and Quantitative Approaches, $7^{\text {th }}$ Ed. Boston, MA: Allyn \& Bacon.

Nordahl, D. (2009). My Kind of Transit: Rethinking Public Transportation. Washington, DC: Island Press.

NYDOT/MTA [New York Dept. of Transportation/Metropolitan Transporation Authority] (2009a). Introduction to Bus Rapid Transit: Phase II. Retrieved from: web.mta.info/mta/planning/sbs/docs/intro_to_brt_phase2.pdf

NYDOT/MTA [New York Dept. of Transportation/Metropolitan Transporation Authority]. (2009b). Bx12 Select Bus Service One Year Report: October 2009. Retrieved from: http://web.mta.info/mta/planning/sbs/docs/Bx12-SBS-OneYearReport.pdf

NYDOT/MTA [New York Dept. of Transportation/Metropolitan Transporation Authority]. (2013). Select Bus Service and BRT: The New York City Experience. Conference presentation at Defining Bus Rapid Transit Workshop, Transportation Research Board Annual Meeting 2013. Retrieved from: http://www.nbrti.org/TRB2013 BRT Workshop.html

NYPIRG [New York Public Interest Research Group]. (December 19, 2013). News Release. Retrieved on March 1, 2014 from: http://www.straphangers.org/pokeyaward/13/

Pessaro, B., M.E. Dowell, M. Gonzales, and A.R. Danaher. (2011). Bus Rapid Transit Applications Phase 2. Report for Florida Dept. of Transportation. Retrieved from: http://www.nbrti.org/docs/pdf/BRT_Applications_PhaseII_Report_Final12-08-2011.pdf

Pisarski, A. (2006). Commuting in America III: The Thirds National Report on Commuting Patterns and Trends. Report for the Transportation Research Board. Washington, DC. Retrieved from: http://www.trb.org/main/blurbs/156993.aspx

Roschlau, M.W. (2007). Public transport policy in Canada and the United States: Developing political commitment from the federal government. Research in Transportation Economics 22, 91-97.

Ratchford, S. (March 28, 2014). Bus stop talk: Candidates spar over long term fix. Nova Res Urbis: Toronto Edition.

Roseland, M. (2012). Toward Sustainable Communities, $4^{\text {th }}$ Ed. Gabriola Island, BC: New Society.

Sadoway, M. (2012). Access to opportunity: The urgency of public transit to Toronto's tower communities. Unpublished academic paper. Toronto, ON: Ryerson University.

Sadoway, M. (2013). Public transit funding and the power to tax: Considering operating revenues for Canadian public transit in light of the public transit funding crisis in the United States. Unpublished academic paper. Toronto, ON: Ryerson University.

Sakaria, N., \& Stehfest, N. (2013). Millennials \& Mobility: Understanding the Millennial Mindset and New Opportunities for Transit Providers. Transit Cooperative Research Program.

Sendich, E. (ed.)(2006). Planning and Urban Design Standards. Hoboken, NJ: John Wiley and Sons.

Simpsons Wiki (n.d.). Still of Crackton bus stop from The Simpsons episode "Lost Our Lisa." Retrieved from: http://simpsons.wikia.com/wiki/Crackton

Simpsons Wiki (n.d.). Still of the end of the line from The Simpsons episode "Lost Our Lisa." Retrieved from: http://simpsons.wikia.com/wiki/End_of the_Line

Sparling, A. (April 2, 2013). Riding the "loser cruiser." Blog post on Canada Writes: Hyperlocal. Viewed on April 1, 2014 at: http://hyperlocal.cbc.ca/mediadetail/10658062-Riding-the-\%22Loser-Cruiser 
Spokane Transit. (2014). Stop consolidation plan. Website viewed on November 30, 2013. https://www.spokanetransit.com/about-sta/view/stop-consolidation-plan

Statistics Canada. (2012). Data from National Household Survey, 2011. From: Commuting to work. Website viewed on April 5, 2014 at http://www12.statcan.gc.ca/nhs-enm/2011/as-sa/99-012-x/99-012x2011003_1-eng.cfm

Stewart, G. and J. Thorne. (2010). Tower Neighbourhood Renewal in the Greater Golden Horseshoe: An Analysis of High-Rise Apartment Tower Neighbourhoods Developed in the Post-War Boom (19451984). Retrieved from City of Toronto Tower Renewal website: http://www.toronto.ca/tower_renewal/reports.htm

Stewart, G. et al. (2012). Toward Healthier Apartment Neighbourhoods: A Healthy Toronto by Design. Retrieved from City of Toronto Tower Renewal website: http://www.toronto.ca/tower renewal/reports.htm

Stewart, J. (2013). Flickr user. Septa 2013 Nova LFS \#7300. Retrieved from: www.flickr.com/photos/m877/10126153625

Stocker, T.F., D. Qin, G.-K. Plattner, M. Tignor, S.K. Allen, J. Boschung, A. Nauels, Y. Xia, V. Bex and P.M. Midgley (eds.). (2013). IPCC, 2013: Summary for Policymakers. In: Climate Change 2013: The Physical Science Basis. Contribution of Working Group I to the Fifth Assessment Report of the Intergovernmental Panel on Climate Change. Retrieved from: http://www.climatechange2013.org/images/report/WG1AR5_SPM_FINAL.pdf

Suzuki, H., R. Cervero, K. Iuchi. (2013). Transforming Cities with Transit: Transit and Land-Use Integration for Sustainable Urban Development. Report for the World Bank. Retrieved from: https://openknowledge.worldbank.org/handle/10986/12233

Thompson, G., Brown, J. R., \& Bhattacharya, T. (2011). What Really matter for Increasing Transit Ridership: A Statistical Analysis of How Transit Level of Service and Land Use Variables Affect Transit Patronage in Broward County, Florida. Transportation Research Board.

Thomson Reuters. (March 23, 2014). Global warming means food, water shortages warns UN report. CBC News. Retrieved from: http://www.cbc.ca/news/technology/global-warming-means-food-watershortages-warns-un-report-1.2583368

Tomer, A. (2011). Transit Access and Zero- Vehicle Households. Brookings Institute. Washington DC: Brookings Institute.

Tomer, A., Kneebone, E., Puentes, R., \& Berube, A. (2011). Missed Opportunity: Transit and Jobs in Metropolitan America. Brookings Institute. Washington DC: Brookings Institute.

Topping, D. (February 21, 2013). Why's the Dufferin bus so awful. Blog post on The Grid Toronto. Viewed on April 10, 2014 at http://www.thegridto.com/city/local-news/whys-the-dufferin-bus-soawful/

TTC Riders. (March 6, 2014). TTC Sardines. Viewed on March 9, 2014, at TTC Riders website: http://www.ttcriders.ca/ttcsardines/

TTC [Toronto Transit Commission]. (March 21, 2007). Toronto Transit City Light Rail Plan. Report to commission.

TTC [Toronto Transit Commission]. (August 29, 2009). Transit City Bus Plan. Report to commission. Retrieved from: http://ttc.ca/About the TTC/Transit Planning/index.jsp

TTC [Toronto Transit Commission]. (May 11, 2011). Opportunities for improved bus service on Finch Avenue. Report to Commission.

TTC [Toronto Transit Commission]. (2013). 2012 Operating Statistics web page. Viewed at: http://ttc.ca/About_the_TTC/Operating_Statistics/2012.jsp on Sept. 25, 2013.

TTC [Toronto Transit Commission]. (2014a). Service Summary: March 30, 2014 to May 10, 2014. Retrieved from: http://ttc.ca/About the TTC/Transit Planning/index.jsp

TTC [Toronto Transit Commission]. (2014b). 2014 Ride Guide. Retrieved from: http://ttc.ca/images/fixedImages/TTC_Rideguide_c.pdf

United Way Toronto. (2012). Poverty by Postal Code 2: Vertical Poverty. Retrieved from City of Toronto Tower Renewal website: http://www.toronto.ca/tower_renewal/reports.htm 
US EPA [United States Environmental Protection Agency] (2013). Sources of Greenhouse Gas Emissions. Website viewed on March 21, 2014:

http://www.epa.gov/climatechange/ghgemissions/sources/transportation.html\#Reducing

Vuchic, V. R. (1999). Transportation for Livable Cities. New Brunswick, NJ: CUPR Press.

Vuchic, V. R. (2005). Urban Transit: Operations, Planning and Economics. Hoboken, NJ: Wiley.

Vuchic, V. R. (2007). Urban Transit: Systems and Technology. Hoboken, NJ: Wiley.

Walker, J. (2008). Purpose-driven public transport: Creating a clear conversation about public transport goals. Journal of Transport Geography 16, pp. 436-442.

Walker, J. (June 25, 2009). Frequent network maps: An obvious idea that took forever to happen. Blog post on Human Transit. Viewed November 3, 2013: http://www.humantransit.org/2009/06/frequentnetwork-maps-an-obvious-idea-that-took-forever-to-happen.html

Walker, J. (March 4, 2011a). Seoul: Buses that tell you where they go? Blog post on Human Transit. Viewed November 3, 2013: http://www.humantransit.org/2011/03/seoul-buses-that-tell-you-wherethey-go.html

Walker, J. (April 24, 2011b). Basics: walking distance to transit. Blog post on Human Transit. Viewed April 5, 2013: http://www.humantransit.org/2011/04/basics-walking-distance-to-transit.html

Walker, J. (2012). Human Transit: How Clearer Thinking about Public Transit Can Enrich Our Communities and Our Lives. Washington, DC: Island Press.

Walker, J. (March 28, 2013). Branding individual routes: too many colors, or the gold standard of legibility? Blog post on Human Transit. Viewed March 28, 2014: http://www.humantransit.org/2013/03/branding-individual-routes-too-many-colors-or-the-goldstandard-of-legibility.html

Webber, E., E. Arpi, and A. Carrigan. (2011). From Here to There: A Creative Guide to Making Public Transport the Way to Go. EMBARQ report. Retrieved from: http://embarq.org/research/publication/here-there

Young, G. (2012). Photo of Calgary Transit bus and stop. From Markusoff, J. (December 7, 2012). Calgary Transit releases RouteAhead plan: More transit, less parking, higher rush-hour fares planned. The Calgary Herald. Retrieved from:

www.calgaryherald.com/news/calgary/Calgary+Transit+releases+RouteAhead+plan/7668659/story.ht $\underline{\mathrm{ml}}$ 